NASA Technical Memorandum 84303

\title{
Optimal Short-Range Trajectories for Helicopters
}

G. L. Slater and H. Erzberger

\author{
LIBRARY COBPY \\ FFR Y - 个Q83 \\ LANGLEY RESEARCH CENTER \\ LIBRARY, NASA \\ HAMPTON, VIRGINIA
}

\section{N/Sก}

National Aeronautics and

Space Administration 
NASA Technical Memorandum 84303

\section{Optimal Short-Range Trajectories for Helicopters}

G. L. Slater, University of Cincinnati, Cincinnati, Ohio 45221

H. Erzberger, NASA Ames Research Center, Moffett Field, California 94035 
Page intentionally left blank 
TABLE OF CONTENTS

Page

LIST OF SYMBOLS . . . . . . . . . . . . . . . . . . . . . . . v

SUMMARY . . . . . . . . . . . . . . . . . . . . . . . . . . . . I

1. INTRODUCTION . . . . . . . . . . . . . . . . . . . . . . 1

2. DEVELOPMENT OF A HELICOPTER PERFORMANCE MODEL . . . . . . . . . . . . . . 2

2.1 Cruise Power Required . . . . . . . . . . . . . . . . . 3

2.2 Propulsive Model ....................... 4

2.3 Climb-Descent Calculations ................ 5

3. FORMULATION OF OPTIMAL TRAJECTORY PROBLEM . . . . . . . . . . . . . 6

3.1 Mathematics of Optimization . . . . . . . . . . . . 6

3.2 Properties of Optimal Controls . . . . . . . . . . . . . . 9

3.3 Behavior of Optimal Solutions as $h+h_{C R}$. . . . . . . . . . . . 13

4. NUMERICAL RESULTS . . . . . . . . . . . . . . . . . . . . 16

4.1 Characteristics of Fuel Optimal Trajectories . . . . . . . . . . . . 16

4.2 Speed Variation on Optimal Trajectories . . . . . . . . . . . . . 18

4.3 Effect of Winds . . . . . . . . . . . . . . . . . . . : 18

4.4 General Cost Optimization ................. . . . . 19

5. CONCLUDING REMARKS . . . . . . . . . . . . . . . . . . . 20

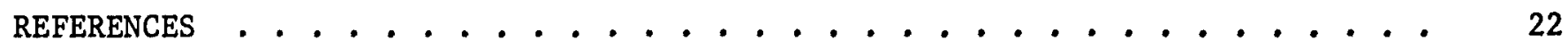

TABLES . . . . . . . . . . . . . . . . . . . . . . . 23

FIGURES . . . . . . . . . . . . . . . . . . . . . . . . 24 
Page intentionally left blank 


\section{LIST OF SYMBOLS}

A

$$
a, b
$$

$\overline{\mathrm{C}}_{\mathrm{L}}$

$\mathrm{C}_{\mathbf{T}}$

$c_{d}$

$c_{1} 1=1, \ldots .3$ $c_{T}, c_{F}$

F

$\mathrm{F}_{\mathrm{CR}}$

$F_{\max }$

$\mathrm{F}_{\mathrm{R}}$

$f_{e}$

$\mathrm{H}$

h

$\mathrm{J}$

$\mathrm{P}_{\mathrm{I}}, \mathrm{P}_{\mathrm{O}}, \mathrm{P}_{\mathrm{P}}$

$P_{\min }, P_{\max }$

$\mathrm{P}_{\mathbf{R}}$

$P_{0}$

$\mathrm{R}_{\mathrm{CR}}$

$\mathrm{R}_{F}$

$\mathrm{T}$

V

$\mathrm{V}_{\max }$

$v_{t}$ rotor reference area

coefficients in the fuel-flow equation

average rotor-1ift coefficient, $\frac{6 C_{T}}{\sigma}$

thrust coefficient, $\frac{\mathrm{T}}{\sigma \mathrm{AV}_{\mathrm{t}}^{2}}$

average rotor-drag coeffictent

coefficlents in the curve fit for required power

cost weighting factors for time and fuel, respectively

integrand of cost function

cost integrand $F$ at cruise altitude $P=P_{R}\left(V_{C R}\right)$

cost integrand $F$ at $P=P_{\max }$

cost integrand $F$ at $P=P_{R}(V)$

helicopter drag area

variational Hamiltonian

a1titude

cost function

induced, parasite, and rotor profile power

minimum and maximum limits on the avallable power

power required for level-flight cruise

constant term in equation for $\mathrm{P}_{\mathrm{DST}}^{*}$

cruise range

specified total range

thrust

airspeed

maximum allowable airspeed

rotor-tip speed 


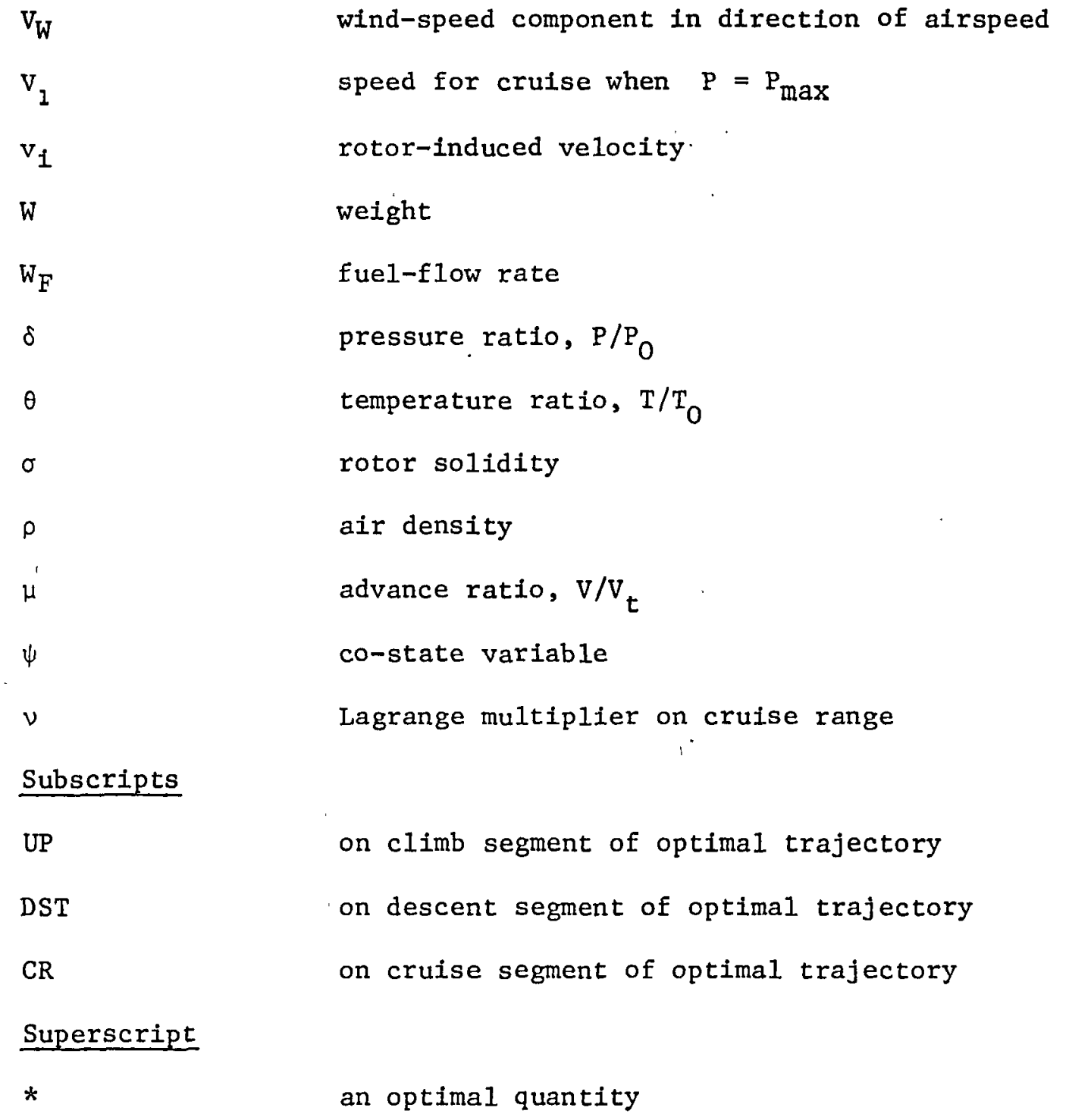


OPTIMAL SHORT-RANGE TRAJECTORIES FOR HELICOPTERS

\author{
G. L. S1ater \\ University of Cincinnati
}

H. Erzberger

Ames Research Center

\title{
SUMMARY
}

An optimal flightpath algortthm using a simplified altitude state model and an a priorl climb-cruise-descent flight proflle has been developed and applied to determine minimum fuel and minimum cost trajectories for a helicopter flying a fixed-range trajectory. In addition, a method is developed for obtaining a performance model in simplified form which is based on standard flight-manual data and which is applicable to the computation of optimal trajectories. The entire performance-optimization algorithm is simple enough that on-line trajectory optimization is feasible with a relatively small computer.

The helicopter model used in this study is the Sikorsky S-61N. The results show that for this vehicle the optimal flightpath and optimal cruise altitude can represent a $10 \%$ fuel saving on a minimum-fuel trajectory. The optimal trajectories show considerable variability because of helicopter weight, ambient winds, and the relative cost trade-off between time and fuel. In general, "reasonable" variations from the optimal velocities and cruise altitudes do not significantly degrade the optimal cost.

For fuel-optimal trajectories, the optimum cruise altitude varies from the maximum $(12,000 \mathrm{ft})$ to the minimum $(0 \mathrm{ft})$ depending on helicopter weight. If time of flight is an important component of the cost function, then significant reductions in flight time from the minimum-fuel trajectory are achieved with only minor increases in fuel cost.

\section{INTRODUCTION}

The unique hover and low-speed capabilities of the helicopter have made this vehicle an important mode of transportation for many applications. General usage of helicopters for commercial application has been limited, however, by the relatively high cost of fuel and flight time for this vehicle, in comparison to the conventional fixed-wing aircraft. While flightpath optimization seems particularly attractive as a means of minimizing these costs, two factors have tended to limit the development of specified operational procedures to allow the pllot to fly optimized flightpaths. These are: (1) The performance characteristics of the helicopter are quite complex and exhibit wide variations in weight and altitude. These changes cause subsequent major differences in the character of the optimal paths. (2) Because the hellcopter is a relatively low-speed vehicle, atmospheric winds also play a significant role in determining the shape of the optimal trajectories. Unless accurate knowledge of winds is available, a computed optimal trajectory may be significantly in error.

One of the first attempts at flightpath optimization was done by Schmitz (ref. 1) who investigated the takeoff problem for a heavily loaded helicopter using a 
variational approach and subsequent1y tested a "suboptimal" implementation of this control policy (ref. 2). The work of 01sen (ref. 3) was directed at onboard optimization of climb and cruise trajectories but utilized only a classical quasi-steady performance approach.

The purpose of this study is to develop a synthesis procedure to allow onboard generation of "optimal" trajectories for helicopters. for arbitrary weight and wind conditions. In particular, trajectories are determined which minimize a cost function chosen as a weighted sum of time and fuel such that time, fuel, or "cost" can be minimized by appropriate selection of the weighting factors. The analytical procedure is based on the method used by Erzberger for fixed-wing aircraft. The method is specialized here to apply to a performance model representative of a helicopter. Much of the effort in this study has been toward the generation of an appropriate performance model which reflects the variability in the true vehicle, yet is simple enough to allow onboard, real-time computation of trajectories. In this report we have speclalized our study to the Sikorsky S-61N helicopter. Section 2 of this paper outlines the performance model used in this study. The development of the optimization procedure is shown in section 3. The essential characteristics of the optimal trajectories and differences between these results and the comparable fixed-wing results are emphasized.

Finally, the application of the optimization algorithm and representative optimal trajectories for the $S-61 \mathrm{~N}$ helicopter are shown in section 4 .

\section{DEVELOPMENT OF A HELICOPTER PERFORMANCE MODEL}

In the development of a performance model for the helicopter, two goals influence our approach. The first goal is to recognize that the primary aim of this effort is to develop an on-line procedure such that operational helicopters with only moderate onboard computational capability can utilize this model to perform on-line trajectory optimization. The second is to ensure that the model is accurate enough over the entire operating envelope of the vehicle so that "optimal" trajectories that are computed using this model will not deviate significantly from the "true" optimal policy. This "true" optimal policy is of course unknown and hence it is impossible to check this second attribute directly. Rather, the accuracy of our model is gauged by comparing the predicted performance with the performance values given in the helicopter flight manual (ref. 4). To implement the flightpath-optimization algorithm three performance quantities are required. These are:

(1) Power for level flight (cruise power).

(2) Rate-of-climb and rate-of-descent data.

(3) Engine power available and fuel-flow data.

These three items are needed for all velocity and altitudes within the vehicle-flight envelope as well as for the range of weights and engine-power settings. Our treatment of each of these items is found in succeeding sections. 


\subsection{Cruise Power Required}

The difficulties of analytically modeling nonaxial flow through a rotor, and accurately accounting for various important effects such as stall, compressibility, etc., make a strictly analytical approach to this problem unreasonable. Yet without some account of the significant effects on required power caused by these items the mathematics of the optimization procedure frequently lead to invalid or nonsenstcal results. The approach taken in this report is to use only a simple phenomenological model based on momentum and blade element theories. The flight manual data are then fit to this simple model using variable coefficients that are functions of vehicle weight and altitude:

We consider the power required for level cruise to be of the form

$$
\mathrm{P}_{R}=c_{1} \mathrm{P}_{\mathrm{I}}+\mathrm{c}_{2} \mathrm{P}_{\mathrm{O}}+\mathrm{c}_{3} \mathrm{P}_{\mathrm{P}}
$$

The terms $P_{I}, P_{0}$, and $P_{P}$ are analytical models of the induced, parasite, and rotor profile powers, respectively (see a text such as Bramwell (ref. 5) or Gessow and Myers (ref. 6)).

The induced power $P_{I}$ which uses the Glauert approximation is written

$$
\mathrm{P}_{\mathrm{I}}=\mathrm{Tv}_{1}
$$

where $T$ is the rotor thrust and $v_{i}$ is the induced velocity given implicitly by

$$
v_{1}=\frac{T}{2 \rho A \sqrt{v^{2}+v_{i}^{2}}}
$$

In our model we use the assumption $\mathrm{T}=\mathrm{W}$.

The parasite power represents the power dissipated by fuselage and hub drag and is written:

$$
P_{0}=\frac{1}{2} f_{e} \rho V^{3}
$$

The rotor profile power, that is, the power dissipated by the rotating blades, is given by the simple blade element expression (ref. 6)

$$
\mathrm{P}_{\mathrm{P}}=\frac{1}{8} \sigma \mathrm{c}_{\mathrm{d}}\left(1+4 \cdot 7 \mu^{2}\right) \rho \mathrm{AV}_{t}^{3}
$$

where $\mu$ is the advance ratio $\left(V / V_{t}\right)$. Numerical values for the parameters of equations (2.3)-(2.5) for the $S-61 \mathrm{~N}$ are shown in table 2.1 .

These power expressions are quite simplistic and neglect several important terms such as nonuniform rotor inflow, azimuthal variation of drag coefficlent, and additional unmodeled power terms such as the tail rotor power. The model is qualitatively correct, however, and becomes quite accurate when the coefficients $c_{1}, c_{2}, c_{3}$ are obtained by a least-squares $f$ it of this model to the flight manual data. 
Several methods were used to fit a set of coefficients $c_{1}, c_{2}, c_{3}$ to the flight data. In one method, labeled "model $B$ " a least-squares flt was obtained for a range of weight and altitude combinations. At each weight-altitude combination, the cruise-power data from the flight handbook was discretized (at 10 knot increments) and the coefficients obtained from the least-square algorithm. The quality of the curve fit was good as observed in figures 2.1(a)-2.1(d). For low weights and altitudes the coefficients $c_{1}$ are close to $I$ and behave consistently, indicating that the simple power model expression (2.1) is Indeed a good approximation to the data. At high altitudes and welghts, the behavior of the coefficients is erratic, indicating difficulty in fitting to the simple model (see figs. 2.2(a)-2.2(c)). The source of the difficulty can be partially resolved by replotting the estimated coefficients as a function of thrust coefficient $c_{T}\left(c_{T}=W / \rho V_{t}^{2} A\right)$ in figures $2.3(a)-2.3(c)$. At high thrust coefficients (corresponding to high rotor-lift coefficients) the erratic variation in fit coefficients (particularly $c_{2}$ and $c_{3}$ ) is an indication that the simple rotor power expression (2.1) is inadequate to model the true power variation with speed. In particular, it is apparent that unmodeled variations with speed in the rotor profile power are being absorbed into the body drag term which has a $V^{3}$ variation. To improve the quality of the model the ad hoc stall and compressibility corrections given by Keys (ref. 7) were included in the least-square algorithms. These corrections did little to improve the consistency of the coefficients and were subsequently omitted.

The primary concern in using these data in the power model is the necessity of interpolating between points to obtain data for the intermediate weights and altitudes. The optimization algorithm is sensitive to derivative information; hence, there is concern about the validity of the trajectories obtained in this case. To improve upon the smoothness of the model an alternate fit technique was applied which assumed that for each weight the coefficients $c_{1}, c_{2}, c_{3}$ were linear functions of altitude. The resultant coefficients are shown in figure 2.2 labeled as " $A$ " Model. This method does indeed improve the smoothness of the fit coefficients; however, the quality of fit, particularly at high weight and altitude, is decreased as seen in figure 2.4. In determining the optimal flightpaths, primary use was made of this smoothed "A" Model. Comparisons of flightpaths computed from the two models are used to indicate the sensitivity of the trajectory generating algorithm to the slight differences in the simplified performance model.

Mass density of the air is the primary atmospheric parameter which determines aerodynamic forces (temperature is significant if Mach effects are considered). Consequently, in parameterizing a model based on altitude it is assumed that "density altitude" is the appropriate definition to use. Since the flight-manual cruise data are presented for the standard atmosphere, the effect of using this model in a nonstandard atmosphere cannot be evaluated at this time.

\subsection{Propulsive Model}

The S-6IN is a dual-turbine-engine-powered helicopter using one of two engine models currently available. These are the General Electric CT58-110 engine having a maximum continuous power (MCP) rating of 1050 SHP and the GE CT58-140 with an MCP of 1250 SHP per engine. The flight manual contains complete data for both engines; however, in this report only the performance with the CT58-140 engine is discussed. Engine power available is shown as a function of altitude in figure 2.5 for standard atmosphere conditions. Performance for off-nominal temperatures is available in the manual but was not used in this report. 
Engine fuel-flow characteristics corrected for altitude effects are shown in figure 2.6. Note that for this engine the fuel flow is a linear function of power at all altitudes. Data are avallable in the manual only at the two altitudes, sea level and $5000 \mathrm{ft}$. . Using standard engine normalization techniques these data are extrapolated to other conditions by using the "corrected" fuel flow $W_{F_{C}}=W_{F} / \delta \sqrt{\theta}$ and the corrected power $\mathrm{HP}_{\mathrm{C}}=\mathrm{HP} / \delta \sqrt{\theta}$, where $\delta=\mathrm{p} / \mathrm{p}_{0}, \theta=\mathrm{T} / \mathrm{T}_{0}$ are the pressure and temperature ratios, respectively. This scaling is validated for the current engine by noting that under this transformation the corrected fuel flows for $h=$ sea level and $h=5000 \mathrm{ft}$ coalesce to a single curve.

Optimum steady state cruise performance can be established by using the performance models of the previous section in conjunction with the fuel-flow data. The parameter $\left(W_{F} / V\right)$ (dimensionally the welght of fuel expended per unit distance traveled) is referred to in this report as the "cruise cost." In addition to its importance in conventional quasi-steady performance calculations, this quantity is shown in succeeding sections of this report to be of fundamental importance in determining the structure of the fuel optimal trajectorles. For each alt1tude and welght the minimum fuel cruise cost $\left(W_{F} / V\right) *=\min _{V}\left(W_{F} / V\right)$ and the corresponding optimum cruise speed $V^{*}=\arg \min _{\mathrm{V}}\left(W_{F} / V\right)$ are determined. Variations in these quantities for each of the two performance models of the previous section are shown in figures 2.7 and 2.8. We expect that the minimum cruise cost of the model $B$ is reasonably accurate at each of the match points. The smoothed model (A) agrees very well at the low gross weight $(13,000-15,000 \mathrm{lb})$ and is a poor fit only for the heavy weights $(W=17,000-19,000 \mathrm{lb})$ at the higher altitudes. The large discrepancy at the high altitude for $W=19,000 \mathrm{lb}$ is not of significance since the optimal trajectories do not enter this region. At the intermediate weight, $W=17,000 \mathrm{lb}$, the two models predict opposite trends with increasing altitude. In this area the fuel optimal trajectories must be examined carefully to assure that the computed optimal performance is not significantly sensitive to potential modeling errors.

The minimization shown in figures 2.7 and 2.8 was done without consideration of the operating limits imposed upon the S-61N. Superimposed with $V^{*}$ on figure 2.8 are the handbook $V_{N E}$ (velocity-never-to-exceed) curves. It is seen that the unconstrained minimization results in optimal cruise speeds consistently falling outside the $V_{N E}$ curves at the higher altitudes (it should be pointed out that handbook cruise data are also frequently outside this boundary). In subsequent trajectory minimizations $V_{N E}$ is used as an upper limit on the allowable speed; hence, the cruise cost shown in figure 2.7 is frequently not achieved.

\subsection{Climb-Descent Calculations}

Cruise-power curves of helicopter in level flight cannot be directly applied to the computation of climb performance, unlike those for the fixed-wing aircraft. The reason is that, in contrast to the fixed-wing aircraft, the helicopter in a climb experfences very little fuselage rotation. Consequently, a vertical velocity component significantly affects the inflow into the rotor; hence, the force and power characteristics may change significantly between level flight and maximum climb rate, though in a continuous way. Keys points out in his report (ref. 7) that climb in a helicopter is affected by an increase in the efficiency of producing thrust, download on the fuselage, increased transmission losses and increases in tail rotor power, all of which have no analog in fixed-wing aircraft. 
Using a technique suggested by Keys (ref. 7) the helicopter climb is simplified by introducing an empirical climb (or descent) factor and writing the climb rate $h$ as

$$
\left.\dot{\mathrm{h}}=\mathrm{k}_{(}\right)\left(\mathrm{P}_{\mathrm{A}}-\mathrm{P}_{\mathrm{R}}\right) / \mathrm{W}
$$

where ( ) indicates either climb or descent, $\mathrm{P}_{\mathrm{A}}$ is the rotor-shaft power available, and $P_{R}$ is the level-flight cruise power required. For the climb factor Keys reports typical values as $k_{C L B} \cong 0.70-0.85$. The corresponding descent factor $k_{D S T} \cong 1$.

The climb factor for the $S-61 N$ is estimated by comparing the flight manual maximum-rate-of-climb data to the computed maximum-rate-of-climb data using equation (2.6). The factor becomes difficult to assess accurately for very low rates of climb because of inconsistencies between the cruise data and climb data published in the flight manual (ref. 4). A summary of the computed climb factors for a number of points is shown in figure 2.9. On the basis of these data a climb factor of 0.75 , shown as a dashed line in figure 2.9, is used throughout this report.

Limited descent data obtained from single-engine operation data indicate that $k_{D S T} \cong 1$ is reasonable in the descent phase of the trajectory. The relationship of these factors to the structure of the optimal trajectories is discussed in the next section.

In the case of fixed-wing aircraft, potential energy (altitude) and kinetic energy (velocity) are often assumed to be interchangeable and in fact if $E=\left(h+V^{2}\right) / 2 g$, then $\dot{E}=\left(P_{A}-P_{R}\right) / W$ is a frequently used performance relation. For the helicopter, it is seen that potential energy changes are complicated by the climb and descent factors. We speculate also that when undergoing velocity changes, an acceleration factor can be introduced, such that

$$
\frac{d}{d t} \frac{V^{2}}{2 g}=k_{A C C} \frac{P_{A}-P_{R}}{W}
$$

The numerical value of such an acceleration factor is needed if a true-energy-type analysis is to be performed. Unfortunately, only little data are available at the present time to allow determination of such a factor. For the performance analysis carried out in the later sections of this report, this problem is circumvented by neglecting kinetic-energy effects on the optimal trajectories. The validity of this assumption is discussed in section 4 .

\section{FORMULATION OF OPTIMAL TRAJECTORY PROBLEM}

\subsection{Mathematics of Optimization}

Using the helicopter performance model of the previous section, we will examine fixed-range trajectories which optimize some performance index. Typically, we may be interested in minimum fuel or minimum operating cost, but, in general, we assume the optimization problem can be formulated as minimization of an integral of the form

$$
J=\int_{0}^{t_{f}} F d t
$$


The optimal trajectory is a determination of the altitude $h$ and range $x$ as functions of time as well as the supplementary variables such as speed, power setting, flightpath angle, etc. such that performance index (3.1a) achieves a minimum value subject to a fixed-range constraint and any additional constraints reflecting operating limits of the vehicle.

The problem as posed fits into the framework of a calculus of variations or "optimal control" problem. While necessary conditions for optimality are rather easy to specify (see, e.g., Bryson and Ho (ref. 8)) numerical computations of the minimizIng trajectory can be a difficult and time consuming task involving iterative solutions of a nonlinear two-point boundary-value problem. This problem can be simplified if we assume at the outset an a priori structure for the optimal trajectory. Using the methodology of Erzberger and Lee (ref. 9) we assume the trajectory can be split into three distinct segments as shown in figure 3.1. These are: (1) an ascent segment, (2) a constant altitude cruise segment, and (3) a descent segment. The cost Integral ( $3.1 a)$ can then be written as

$$
J=\int_{0}^{t_{u p}}(F)_{U P} d t+\int_{t_{D S T}}^{t_{f}}(F)_{D S T} d t+F_{C R} \Delta t_{c r}
$$

To further simplify, we assume the energy per unit weight ("energy height")

$$
h_{e}=h+\frac{v^{2}}{2 g}
$$

is monotonic on the ascent and descent portions of the trajectories and can be used as an independent variable. In the fixed-wing case used by Erzberger, the energy height satisfies

$$
\frac{d h_{e}}{d t}=\left(P-P_{R}\right) / W
$$

where $P$ is the available power from the propulsive system and $P_{R}$ is the power required for equilibrium (constant energy) flight. Also in (3.3), the acceleration normal to the flightpath is considered small. To extend this concept to a rotarywing vehicle requires certain additional assumptions. First, on a helicopter, the rotor itself can serve as a significant energy storage device. If variable rotor speeds are to be considered then rotor energy should be an additional term in (3.2). For this study a fixed rotor speed, which is consistent with the flight manual performance curves, was used. Hence, this term is not present. Second, the performance model of the helicopter discussed in section 2 differentiates changes in potential energy $(h)$ and kinetic energy $\left(V^{2} / 2 g\right)$ by use of the climb, descent, and acceleration factors. This suggests that potential and kinetic energy are not interchangeable on a trajectory as is generally the case with a conventional aircraft. These complications can be suppressed by noting that being an inherently low-speed vehicle, the kinetic-energy term and, in particular, the kinetic-energy changes, are generally fairly small for a helicopter (observe that at $V=100 \mathrm{knots}, \mathrm{V}^{2} / 2 \mathrm{~g} \doteq 443 \mathrm{ft}$ ). Further, since the changes on the optimizing trajectories occur over a fairly substantial time period, it is reasonable then to assume that the kinetic-energy term can be neglected completely, thereby eliminating the need for the acceleration factor. This also implies that the "energy state" to be used in this analysis is more simply just the geometric altitude. Since the ascent and descent portions of the trajectory are disjoint, the energy relation (3.3) can be modified for the helicopter by 
insertion of the respective climb or descent factor on the appropriate segment of the trajectory.

Converting to altitude as the independent variable, the cost function ( $3.1 \mathrm{~b}$ ) can be written as

$$
J=\int_{0}^{h_{C R}}\left[\left(\frac{F}{h}\right)_{U P}+\left(\frac{F}{-\dot{h}}\right)_{D S T}\right] d h+\left(\frac{F}{V+V_{W}}\right)_{C R} R_{C R}
$$

where $V_{W}$ is the wind and $R_{C R}$ is the cruise range. In addition, the range must satisfy

$$
R_{F}=\int_{0}^{t_{U P}}\left(V \cos \gamma+V_{W}\right)_{U P} d t+R_{C R}+\int_{t_{D S T}}^{t_{F}}\left(V \cos \gamma+V_{W}\right)_{D S T} d t
$$

where $\gamma$ is the flightpath angle. Written in terms of $h$ as the independent variable, this becomes

$$
R_{F}=\int_{0}^{h_{C R}}\left[\left(\frac{V \cos \gamma+V_{W}}{\dot{h}}\right)_{U P}+\left(\frac{V \cos \gamma+V_{W}}{-\dot{h}}\right)_{D S T}\right] d h+R_{C R}
$$

The integral constraint ( $3.5 \mathrm{a}$ ) can be more easily treated by introducing a range variable $R(h)$ and rewriting as a differential equation constraint:

$$
\begin{aligned}
\frac{\mathrm{dR}}{\mathrm{dh}} & =\left(\frac{\mathrm{V} \cos \gamma+\mathrm{V}_{\mathrm{W}}}{\dot{\mathrm{h}}}\right)_{\mathrm{UP}}+\left(\frac{\mathrm{V} \cos \gamma+\mathrm{V}_{\mathrm{W}}}{-\dot{\mathrm{h}}}\right)_{\mathrm{DST}} \\
\mathrm{R}(0) & =\mathrm{R}_{\mathrm{CR}} \text { (to be determined) } \\
\mathrm{R}\left(\mathrm{h}_{\mathrm{CR}}\right) & =\mathrm{R}_{\mathrm{F}} \text { (given) }
\end{aligned}
$$

The problem then becomes one of minimizing integral (3.4) while satisfying the differential equation constraint ( $3.5 \mathrm{~b}$ ) subject to boundary conditions (3.6). The control variables in the integra1 (3.4) are the speed $V$ and power available, $P_{A}$, on the climb and descent portions of the trajectory. Unlike the conventional energy-state formulation, large flightpath angles could have easily been incorporated into this analysis if desired. Since the minimizations are performed holding $h$ fixed, $\gamma$ can always be calculated explicitly as a function of $V$ and $P$ as $\gamma=\sin ^{-1}(\dot{h} / V)$. In view of the other assumptions required in this analysis, this refinement was omitted and the small angle assumption was used exclusively in the numerical results presented in this report.

Using the Pontryagin Minimum Principle, this problem is solved by adjoining the differential equation constraint $(3.5 \mathrm{~b})$ to (3.4) using a co-state variable $\psi$. The resultant Hamiltonian can be distributed into climb and descent components as

$$
\mathrm{H}=\mathrm{H}_{\mathrm{UP}}+\mathrm{H}_{\mathrm{DST}}
$$


where

$$
\begin{aligned}
H_{U P} & =\left(\frac{F+\left(V \cos \gamma+V_{W}\right) \psi}{\dot{h}}\right)_{U P} \\
H_{D S T} & =\left(\frac{F+\left(V \cos \gamma+V_{W}\right) \psi}{(-\grave{h})}\right)_{D S T}
\end{aligned}
$$

Additionally, we define the augmented function of end conditions

$$
\Psi_{F}=\left(\frac{F}{V+V_{W}}\right)_{C R}+\nu R_{f}
$$

where $H$ is a function of the variables $V$, and $P$ on both the ascent and descent segments of the trajectory. During cruise we have the single control variable $V_{C R}$. The wind $V_{W}$ is a specified function of altitude on each of the three trajectory segments.

Application of the minimum principle leads to the following necessary conditions:

$$
\begin{aligned}
& \mathrm{V}_{\mathrm{UP}}^{*}, \mathrm{~F}_{\mathrm{UP}}^{*}=\underset{\mathrm{V}, \mathrm{P}}{\operatorname{argmin}}\left(\mathrm{H}_{U P}\right) \\
& \mathrm{V}_{\mathrm{DST}}^{*}, \mathrm{P}_{\mathrm{DST}}^{*}=\underset{\mathrm{V}, \mathrm{P}}{\operatorname{argmin}}\left(\mathrm{H}_{\mathrm{DST}}^{\prime}\right) \\
& V_{C R}=\underset{V}{\operatorname{argmin}}\left(\frac{F}{V+V_{W}}\right)
\end{aligned}
$$

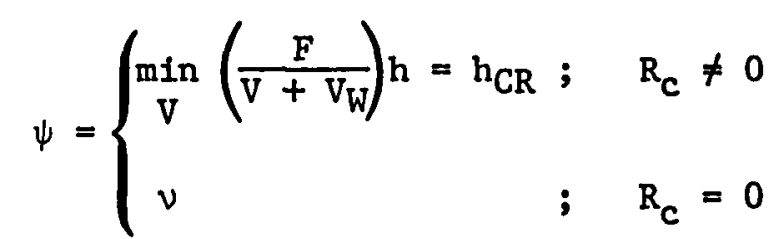

If $h_{C R}$ is a free variable, then at the optimal altitude the transversality condition Is:

$$
\mathrm{H}^{*}+\frac{\partial}{\partial \mathrm{h}_{\mathrm{CR}}} \mathrm{R}_{\mathrm{C}}=0
$$

For a further discussion of these conditions, see Erzberger (ref. 9).

\subsection{Properties of Optimal Controls}

The minimization of $\mathrm{H}_{U P}$ and $\mathrm{H}_{D S T}$ in (3.11) is a double minimization that must be performed at each altitude. For this study we look at functionals of the form:

$$
F=c_{T}+c_{F} W_{F}
$$


where $W_{F}$ is the fuel flow rate, and $c_{T}$ and $c_{F}$ are cost weighting factors for time and fuel, respectively. If $c_{T}=0$ we have the minimum fuel problem. If $c_{F}=0$ we have the minimum time problem. For the model under study, the fuel flow is a linear function of the power available in the form:

$$
W_{F}=a+b P
$$

For the particular problem in this study we show that the avallable power that minimizes HUP or HDST must always lie on the boundary of the admissible set. We consider separately the ascent and descent segments of the trajectory. For simplicity we assume that the wind is zero.

3.2.1 Ascent- In the ascent segment, the rate of climb is given by

$$
\dot{\mathrm{h}}=\mathrm{k}_{\mathrm{CLB}}\left(\mathrm{P}-\mathrm{P}_{\mathrm{R}}\right)
$$

where $P_{R}=P_{R}(V)$ is the cruise power required at some $h, V$. On ascent the power must satisfy the constraint:

$$
\max \left[P_{\min }, P_{R}(V)\right] \leq P \leq P_{\max }
$$

If we consider $V$ as fixed, then $P$ must be chosen to minimize

$$
\left.\begin{array}{rl}
H_{U P} & =\frac{c_{T}+c_{F}(a+b P)-\psi V}{k_{C L B}\left(P-P_{R}\right)} \\
& =\frac{\left(c_{T}+c_{F} a-\psi V\right)+c_{F} b P}{k_{C L B}\left(P-P_{R}\right)}
\end{array}\right\}
$$

The graph of (3.16) is as shown in figure 3.2. Since (3.16) is a bilinear function of $P$, its derivative is nowhere zero and the region $P \leq P_{R}$ is excluded from the allowable control region by (3.15). Consequently, for the ascent segment of the trajectory we have

$$
\mathrm{P}_{\mathrm{UP}}^{*}=\mathrm{P}_{\max }
$$

Since the optimal $P$ is established by (3.17), we can now consider the variation of $\mathrm{H}_{\text {UP }}$ with $\mathrm{V}$.

$$
H_{U P}=\frac{F_{\max }-\psi V}{k_{C L B}\left(P_{\max }-P_{R}\right)}
$$

where $F_{\max }=F\left(P_{\max }\right)$ is now fixed and $P_{R}$ has the general shape shown in figure 3.3. Generally, we can assume the optimal $V$ will lie on the increasing region of $P_{R}$ and must be less than some specified $V_{\max }$ for each altitude. Further $V$ is bounded by $V_{1}$, the equilibrium flight velocity for $P=P_{\max }$. The numerator of (3.18), being linear in $V$ with $F_{\max }$ and $\psi$ both positive, has one zero which we call $V_{z}$, that is, $F_{\max }-\psi V_{z}=0$. Depending upon whether $V_{z}>V_{1}$ or $V_{z}<V_{i}$, the graph of. $H_{U P}$ takes on different shapes as shown in figures $3.4(\mathrm{a})$ and $3.4(\mathrm{~b})$. 
If $V_{1}<V_{\max }, V_{1}$ establishes the upper-velocity boundary. If case (a) occurs $\left(V_{z}>V_{1}\right)$, then there exists a well-defined minimum at $V=V^{*}$ such that

$$
\left.\frac{\mathrm{dH}_{\mathrm{UP}}}{\mathrm{dV}}\right|_{\mathrm{V}=\mathrm{V}^{*}}=0 \quad \text { (Note } \mathrm{H}_{U P}>0, \mathrm{dH}_{U P} / \mathrm{dV}<0 \text { at } \mathrm{V}=0 \text { ) }
$$

If case (b) occurs then $\underset{V \rightarrow V}{\lim } \cdot H_{U P}=-\infty$ and the minimization problem is obviously 111-posed. Observe that by definition, $V_{z}$ satisfies

$$
\frac{F_{\max }}{V_{z}}=\psi=\underset{V}{\min }\left(\frac{F}{V}\right)_{\mid h=h_{C R}}
$$

Consequently, we see that for case (b) to occur

$$
\frac{F_{\max }}{V_{1}}<\frac{F_{\max }}{V_{z}}=\min _{V}\left(\frac{F}{V}\right)_{h=h_{C R}}
$$

That is the optimum cruise cost increases with altitude. Further, if the cruise cost is not an absolute minimum on $\left[0, h_{C R}\right]$ at the cruise altitude, then this case must occur at some point, causing the breakdown in the optimality conditions.

The situation changes slightly if there exists a velocity limit, $V_{\max }$, which makes the equilibrium speed $V_{1}$ unattainable. In this case, as shown in figure 3.5, the minimum of $\mathrm{H}_{U P}$ occurs at $\mathrm{V}=\mathrm{V}_{\max }$. Can this case actually occur? From the definition of $V_{z}$ we have

$$
\frac{F}{V_{\max }}>\frac{F}{V_{z}}=\psi
$$

Hence, the $V_{\max }$ Iimitation in this case forces the helicopter to climb at a speed which is more fuel expensive than at the cruise altitude. Physically this seems to be a realizable situation.

In the alternate case where $\mathrm{V}_{2}<\mathrm{V}_{\max }<\mathrm{V}_{1}$, then $\mathrm{H}_{\mathrm{UP}}^{*}<0$ and $\mathrm{F}_{\max } / \mathrm{V}_{\max }<\psi$. Physically it seems contradictory to even want to climb in this condition since by lowering the applied power (thereby lowering $F$ ) we can cruise at a lower altitude than $h_{C R}$ and expend less fuel per unit distance traveled. This apparent paradox is caused by the fact that we are treating $h_{C R}$ as a fixed limit. Consider. $\underset{V}{\min }(\mathrm{F} / \mathrm{V})$ as a function of altitude, where $F$ is evaluated at the cruise power. If $\underset{\mathrm{V}}{\mathrm{m}}(\mathrm{F} / \mathrm{V})$ is increasing on the interval $\left[\mathrm{h}, \mathrm{h}_{\mathrm{CR}}\right]$ then direct construction shows that a lower cost can be achieved by cruising at $h$ rather than at $h_{C R}$. The optimality of $h_{C R}$ (for small perturbations) must be ascertained by examining the traversality condition (3.1le). This condition is examined later in this section.

3.2.2 Descent- In the descent phase the power must be chosen to satisfy:

$$
\dot{\mathrm{h}}_{\mathrm{DST}}=\left(\mathrm{P}-\mathrm{P}_{\mathrm{R}}\right) / \mathrm{W}<0
$$


Using the same form of the cost function as in the ascent we have

$$
\mathrm{H}_{\mathrm{DST}}=\frac{\mathrm{F}-\psi \mathrm{V}}{\left(\mathrm{P}_{\mathrm{R}}-\mathrm{P}\right) / \mathrm{W}}
$$

where for simplicity we assume $k_{D S T}=1$. For fixed $V$ and a linear fuel-flow function, $\mathrm{H}_{\mathrm{DST}}$. is again bilinear in $\mathrm{P}$. The graph of $\mathrm{H}_{\mathrm{DST}}$ is shown in figure 3.6 .

For any $\mathrm{V}$ it is apparent that the minimum of $\mathrm{H}_{\mathrm{DST}}$ is achieved at the constraint boundary $P=P_{\min }$. We can now set $P=P_{\min }$ and examine the variation of $\mathrm{H}_{\mathrm{DST}}$ with speed $\mathrm{V}$. From (3.2I) with $\mathrm{F}=\mathrm{F}_{\mathrm{min}}$ a constant, the numerator is again a Iinear function of $\mathrm{V}$ with a zero at $\mathrm{V}=\mathrm{V}_{z}$. We deduce then that $\mathrm{H}_{\mathrm{DST}}$ has the properties

$$
\begin{aligned}
& \mathrm{H}_{\mathrm{DST}}\left(\mathrm{V}_{\mathrm{z}}\right)=0 ; \quad \frac{\mathrm{dH}_{\mathrm{DST}}}{\mathrm{dV}}\left(\mathrm{V}_{\mathrm{z}}\right)<0 \\
& \lim _{\mathrm{V} \rightarrow \infty} \mathrm{H}_{\mathrm{DST}}=0^{(-)}
\end{aligned}
$$

Generally, because of the low fuel flow associated with $P_{m i n}$, the value $V_{z}$ is fairly low; hence, the graph of $\mathrm{H}_{\mathrm{DST}}$ is as shown in figure 3.7 . Conditions $(3.22)$ imply that an absolute minimum of $\mathrm{H}_{\mathrm{DST}}$ must occur at some
$\mathrm{V}=\mathrm{V}_{\mathrm{DST}}^{*}$ with $\mathrm{V}_{\mathrm{DST}}^{*}>\mathrm{V}_{\mathrm{z}}$. The minimum may not be achieved if $\mathrm{V}_{\max }<\mathrm{V}_{\mathrm{DST}}^{*}$ but in any event we will always have $\mathrm{H}_{\mathrm{DST}}^{*}<0$.

3.2.3 An alternate descent limit- The use of a fixed minimum-power limit may yield unacceptable descent rates in part's of the flight regime. Rather than specify $\mathrm{P}_{\mathrm{min}}$, an alternate constraint has been implemented to constrain the descent rate

$$
-\dot{\mathrm{h}}_{\mathrm{DST}}=\frac{\mathrm{P}_{\mathrm{R}}-\mathrm{P}}{\mathrm{W}} \leq \dot{\mathrm{h}}_{\max } \text { (constant) }
$$

In view of the previous discussions on the variation of $H_{D S T}$ with $P$, the inequality (3.23) is an equality on the optimum descent trajectory. This implies that on the descent

$$
\mathrm{P}_{\mathrm{DST}}^{*}=\dot{\mathrm{P}}_{\mathrm{R}}-\mathrm{P}_{0}
$$

where " $\mathrm{P}_{0}$ " is a constant depending on the descent rate. The descent Hamiltonian is of the form

$$
H_{D S T}=\frac{c_{T}+c_{F}\left(P_{R}-P_{0}\right)-\psi V}{\left(\dot{h}_{\max }\right)}
$$

For the typical variation of $\mathrm{P}_{\mathrm{R}}$ with $\mathrm{V}$ (fig. 3.4), $\mathrm{H}_{\mathrm{DST}}$ has a well defined minimum at $V=V_{D S T}^{*}$ Generally, $H_{D S T}^{* *}$ is found to be negative. An important observation is that this minimizing speed is independent of the descent rate. 


\subsection{Behavior of Optimal Solution as $h \rightarrow h_{C R}$}

In the fixed-wing case Erzberger and Lee found that the optimal climb/descent speed and power generally blended in smoothly with the corresponding cruise parameters as $h \rightarrow h_{C R}$. In addition a nonzero cruise segment generally only occurred at one altitude - the altitude for optimum cruise, where $\psi$ is a minimum. For the helicopter problem in this report, the assumed linear fuel-flow relationship with power forces the power to be discontinuous at the cruise altitude. We shall show, however, that the velocities at cruise are continuous. In addition it will be shown that the climb and descent coefficients introduced in section 2 cause the cruise behavior of the helicopter to be significantly different from that of the fixed-wing aircraft.

At any altitude below $h_{C R}$ the optimum power on the climb/descent segments are $\mathrm{P}_{\max } / \mathrm{P}_{\min }$ as derived previously. Hence, we $\mathrm{flx}$ the power at these levels to investigate the behavior of the optimal speeds as in the vicinity of $h_{C R}$.

3.3.1 Descent segment- Consider here the case of a fixed descent rate limit

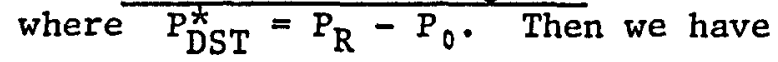

$$
\begin{aligned}
& \mathrm{H}_{\mathrm{DST}}=\frac{\left(\mathrm{c}_{\mathrm{T}}+\mathrm{c}_{F} \mathrm{~W}_{\mathrm{F}}\right)-\psi \mathrm{V}}{\dot{\mathrm{h}}_{\mathrm{DST}}} \\
& =\frac{c_{T}+c_{F}\left[a+b\left(P_{R}-P_{0}\right)\right]-\psi V}{\dot{h}_{D S T}} \\
& =\frac{-c_{F} b P_{0}}{\dot{h}_{D S T}}+\frac{c_{T}+c_{F}\left(a+b P_{R}\right)-\psi V}{\dot{h}_{D S T}} \\
& =\frac{-c_{F} b_{0}}{\dot{h}_{D S T}}+\frac{F_{C R}-\psi V}{\dot{h}_{D S T}}
\end{aligned}
$$

where $F_{C R}=c_{T}+c_{F}\left(a+b P_{R}\right)$ is the cost integrand associated with equilibrium cruise at the speed $V$ and altitude $h$. The optimal descent speed $V_{D S T}^{*}$ satisfies for any $h<h_{C R}$

$$
\frac{\mathrm{dH}_{\mathrm{DST}}}{\mathrm{dV}_{\mathrm{DST}}}=0=\frac{1}{\dot{\mathrm{h}}_{\mathrm{DST}}}\left(\frac{\mathrm{dF}_{\mathrm{CR}}}{\mathrm{dV}_{\mathrm{DST}}}-\psi\right)
$$

By definition we have, however, $\psi=\min \left(\mathrm{F}_{\mathrm{CR}} / \mathrm{V}_{\mathrm{CR}}\right)_{\mathrm{h}=\mathrm{h}_{\mathrm{CR}}}$. Hence,

$$
\frac{d}{d V_{C R}} \frac{F_{C R}}{V_{C R}}=\frac{1}{V_{C R}} \frac{d F_{C R}}{d V_{C R}}-\frac{F_{C R}}{v_{C R}^{2}}=0
$$


or

$$
\left(\frac{\mathrm{dF}}{\mathrm{dV})_{\mathrm{CR}}}\right)_{\mathrm{h}=\mathrm{h}_{\mathrm{CR}}}=\frac{\mathrm{F}_{\mathrm{CR}}}{\mathrm{V}_{\mathrm{CR}}}=\psi
$$

Comparing (3.24) and (3.25) we see that as $h \rightarrow h_{C R}, v_{D S T}+v_{C R}$.

3.3.2 Ascent segment- On the climb segment the optimal ascent speed is given by

$$
\mathrm{V}_{\mathrm{UP}}^{*}=\underset{\mathrm{V}}{\operatorname{argmin}} \frac{\mathrm{F}_{\max }-\psi \mathrm{V}_{U P}}{\mathrm{P}_{\max }-\mathrm{P}_{\mathrm{R}}}
$$

where superfluous constants have been discarded from the Hamiltonian. speeds)

At the minimum (assuming the minimum lies in the interior of the allowable

$$
\frac{\mathrm{dH}_{U P}}{d V_{U P}}=-\frac{\psi}{P_{\max }-P_{R}}+\frac{F_{\max }-\psi V_{U P}}{\left(P_{\max }-P_{R}\right)^{2}} \frac{\mathrm{dP}_{R}}{d V_{U P}}=0
$$

or

$$
\left(P_{\max }-P_{R}\right) \psi-\left(F_{\max }-\psi V_{U P}\right) \frac{d_{R}}{d V_{U P}}=0
$$

For the assumed cost function and the linear fuel-flow relation we have

$$
F_{\max }-F_{R}=c_{F} b\left(P_{\max }-P_{R}\right)
$$

and

$$
c_{F} b \frac{d P_{R}}{d V_{U P}}=\frac{d F_{R}}{d V_{U P}}
$$

Using (3.28a) and (3.28b) in (3.27), we have

$$
\frac{d F_{R}}{d V_{U P}}=\frac{F_{\text {max }}-F_{R}}{F_{\max }-\psi V_{U P}} \psi
$$

The optimum $V_{U \mathrm{P}}^{*}$ is the solution to (3.29) at each $h<h_{\mathrm{CR}}$. From the definition of $\psi$ and relationship (3.25) we note that as $h+h_{C R}$, then $V_{U P}^{*} \rightarrow V_{C R}$ satisfies $(3.29)$ since

$$
\frac{d F_{R}}{d V_{U P}}=\frac{d F_{R}}{d V_{C R}}=\psi
$$


Our conclusion then is that the optimal ascent and descent speeds approach the cruise speed as $\mathrm{h}+\mathrm{h}_{\mathrm{CR}}$.

While the optimal power is discontinuous at cruise we see that as $h+h_{C R}$ and $\mathrm{V} \rightarrow \mathrm{V}_{\mathrm{CR}}$ the hyperbolic varlations of $\mathrm{H}_{U P}$ and $\mathrm{H}_{\mathrm{DST}}$ shown in figures 3.2 and 3.6 tend to a rectilinear hyperbola implying that the Hamiltonians are effectively independent of power in this region. Thus, while the limits of the minimizing values are discontinuous, the Hamiltonian itself is very insensitive to these variations at the point of discontinuity.

3.3.3 Hamiltonian at cruise- The optimal cruise altitude is determined from the transversality condition

$$
\mathrm{H}^{*}+\frac{\partial}{\partial \mathrm{h}_{\mathrm{CR}}} \frac{\mathrm{F}_{\mathrm{CR}}}{\mathrm{V}_{\mathrm{CR}}} \mathrm{R}_{\mathrm{c}}=0
$$

evaluated at $\mathrm{h}_{\mathrm{CR}}$.

Thus it is of interest to examine the behavior of $\mathrm{H}^{*}$ to gain some insight into the nature of the cruise. Since

$$
V_{U P}=V_{D S T}=V_{C R} . \quad \text { at } \quad h=h_{C R}
$$

then

$$
\mathrm{H}^{*}=\mathrm{H}_{\mathrm{UP}}^{*}+\mathrm{H}_{\mathrm{DST}}^{*}
$$

which from (3.18) and (3.21) becomes

$$
H^{*}=\frac{F_{\max }-\psi V_{C R}}{\left(k_{C L B} / W_{U P}\right)\left(P_{\max }-P_{C R}\right)}+\frac{F_{m i n}-\psi V_{C R}}{\left(k_{D S T} / W_{D S T}\right)\left(P_{C R}-P_{\min }\right)}
$$

Using $\psi V_{C R}=F_{C R}$, and the linear fuel-flow function (3.13), equation (3.30) can be written

$$
\begin{aligned}
\mathrm{H}^{*} & =\frac{\mathrm{c}_{\mathrm{F}} \mathrm{b}\left(\mathrm{P}_{\max }-\mathrm{P}_{\mathrm{CR}}\right)}{\left(\mathrm{k}_{\mathrm{CLB}} / \mathrm{W}_{\mathrm{UP}}\right)\left(\mathrm{P}_{\max }-\mathrm{P}_{\mathrm{CR}}\right)}+\frac{\mathrm{c}_{\mathrm{F}} \mathrm{b}\left(\mathrm{P}_{\mathrm{min}}-\mathrm{P}_{\mathrm{CR}}\right)}{\left(\mathrm{k}_{\mathrm{DST}} / \mathrm{W}_{\mathrm{DST}}\right)\left(\mathrm{P}_{\mathrm{CR}}-\mathrm{P}_{\mathrm{min}}\right)} \\
\mathrm{H}^{*} & =\mathrm{c}_{\mathrm{F}} \mathrm{b}\left(\frac{\mathrm{W}_{\mathrm{UP}}}{\mathrm{k}_{\mathrm{CLB}}}-\frac{\mathrm{W}_{\mathrm{DST}}}{\mathrm{k}_{\mathrm{DST}}}\right)
\end{aligned}
$$

Assume that for a short cruise segment, $W_{U P} \cong W_{D S T}=W$. If we consider the case where $\mathrm{k}_{\mathrm{CLB}}=\mathrm{kDST}_{\mathrm{D}}=1$ then $\mathrm{H}^{*}=0$. From (3.11e), $\mathrm{H}^{*}=0$ implies that the optimum cruise range $R_{C R}=0$ except at the optimum cruise altitude $h^{*}$ where

$$
h^{*}=\underset{h}{\operatorname{argmin}}[\psi]
$$

At $h^{*}$, condition (3.11e) gives $0=0$ and the optimum cruise range is determined from the total range constraint. Note that the two terms in $H^{*}$ are $H_{U P}^{*}$ and $H_{D S T}^{*}$ 
implying that for this case these terms are equal in magnitude and opposite in sign.

For the case where the climb and descent factors are not equal

$$
\mathrm{H}^{*}=\mathrm{c}_{\mathrm{F}} \mathrm{bW}\left(\frac{1}{\mathrm{k}_{\mathrm{CLB}}}-\frac{1}{\mathrm{k}_{\mathrm{DST}}}\right)
$$

There exists a nonzero cruise distance at all cruise altitudes given by:

$$
\mathrm{R}_{\mathrm{c}}=-\frac{\mathrm{H}^{*}}{\left(\mathrm{~d} / \mathrm{dh}_{\mathrm{CR}}\right)\left(\mathrm{F}_{\mathrm{CR}} / \mathrm{V}_{\mathrm{CR}}\right)}
$$

Equation (3.33) also confirms our earlier result that the cruise cost must be decreasIng at the cruise altitude since otherwise the cruise range from (3.34) would be negative. As $h_{C R} \rightarrow h^{*}$, the derivative $(d / d h)\left(F_{C R} / v_{C R}\right) \rightarrow 0$ while $H^{*} \neq 0$. Hence, for this case the optimal cruise altitude for any fixed range trajectory is always below the optimal cruise altitude $\mathrm{h}^{*}$.

The use of the climb and descent factors introduces an additional dilemma, however, which is yet to be resolved. For the data used in this report we have assumed (and verified computationally) that $k_{C L B}<k_{D S T}$. For this case $H^{*}>0$ and the optimum range can be ascertained by use of (3.34). The dilemma concerns the hypothetical case where $k_{C L B}>k_{D S T}$. If this case were to occur then $H^{*}<0$. Equation (3.34) can only be satisfied if $\mathrm{F}_{C R} / \mathrm{V}_{\mathrm{CR}}$ is increasing with altitude. This, however, is precisely the case which was disallowed in minimization of $\mathrm{H}_{U P}$, $\mathrm{H}_{\mathrm{DST}}$ at altitudes below crulse.

\section{NUMERICAL RESULTS}

\subsection{Characteristics of Fuel Optimal Trajectories}

A computer program was written which generates the optimal trajectories using the helicopter model and optimization algorithm developed in this report. The program numerically integrates the climb and descent portions of the trajectory optimizing the ascent and descent Hamiltonians at each step, simultaneously. For the cruise segment the cruise cost and speed are computed using a cruise weight computed as the average of the beginning and end weights on the cruise. Since these weights are not known initially, this process is done iteratively until the weights converge. Unless specifically mentioned otherwise, all results in this report are for the case of minimum fuel cost in zero wind.

A typical set of trajectories is as shown in figure 4.1 for an initial weight of $14,000 \mathrm{lb}$. To generate these curves the cruise altitude was first specified, then the cruise range was calculated based on boundary condition ( 3.11 e), which must be satisfied at the optimal altitude and range. A descent rate constraint of $30 \mathrm{ft} / \mathrm{sec}$ was used on all trajectories. As a consequence of a nonunity climb factor $\left(k_{C L B}=0.75, k_{D S T}=1.0\right)$ all trajectories have a nonzero cruise range which in fact shows very little varlation with altitude. The lack of variation is due primarily to the fact that the derivative $\mathrm{d} \psi / \mathrm{dh}$ is almost constant in this entire altitude range. Since the final Hamiltonian $\mathrm{H}^{*}$ is also relatively fixed, the subsequent 
cruise range computed from (3.1le) exhiblts very little variation with altitude. The same is true for moderately higher welghts as shown in figure 4.2.

For welghts less than about $17,000 \mathrm{lb}$, the cruise cost 1 s a monotonically decreasing function of altitude. Hence, for longer ranges, the optimal cruise altitude is increasingly higher. For the S-61N the maximum allowable altitude is $12,000 \mathrm{ft}$. At this altitude and using an initial welght of $14,000 \mathrm{lb}$, the natural boundary condition on altitude yields a trajectory with total range of about $33 \mathrm{n}$. mi. (see fig. 4.1). For a trajectory with a specified range greater than this value, the minimum fuel trajectory cruises at the limit altitude of $12,000 \mathrm{ft}$. At this altitude, the cruise segment is determined not from the transversality condition, but from the total range condition:

$$
R_{C R}=R_{F}-\left(R_{U P}+R_{D S T}\right)
$$

It is important to note that the mathematically optimum altitude is very significantly a function of initlal weight. The most important parameter in establishing the optimum altitude is the variation with altitude of the quasi-steady "cruise cost" $\psi=\min _{V}\left(W_{F} / V\right)$. Using our variational approach, the optimum cruise altitude is at or slightly below, the altitude for minimum $\psi$. At low initial weights (see fig. 2.7) the optimum cruise is at $h_{\max }=12,000 \mathrm{ft}$. At high weights $(\approx 19,000 \mathrm{lb})$ the opt1mum altitude is at $h_{\text {min }} \approx 0$.

Although the curves of cruise cost change smoothly with weight, the optimum altitude changes rather abruptly from $h_{\max }$ to $h_{\min }$ at a weight slightly greater than $17,000 \mathrm{lb}$. It should be pointed out that at the higher weights and higher altitudes, the smoothed power model (A) departs significantly from the pointwise model (B). Thus, while at $17,0001 \mathrm{~b}$ the smoothed model (A) predicts improved cruise performance up to $h_{\max }$, the pointwise model (B) predicts rapidly deteriorating performance for altitudes greater than about 8,000 ft. Similarly at the 19,000 lb weight, for altitudes above 8,000 , the smoothed model (A) predicts substantially less degradation than the pointwise model (B).

The significance of these differences can be more easily evaluated by observing the fuel variation on minimum fuel trajectorles, where the cruise altitude is constrained at a nonoptimal value. Figure 4.3 demonstrates this effect using the smoothed (A) model. For the $14,000 \mathrm{lb}$ vehicle, cruise at the optimal altitude of $12,000 \mathrm{ft}$ represents about a $5 \%$ improvement over cruise at $1,000 \mathrm{ft}$. Since the two fitting techniques ( $A$ and $B$ ) agree so closely in this low-weight range these results are felt to be reliable and represent a true fuel savings. For the heavy weight of $19,000 \mathrm{lb}$, the figure similarly predicts a substantial fuel saving of about $10 \%$ by cholce of the lowest possible cruise altitude (here 1,000 ft). Comparison of the optimal cruise costs in figure 2.7 indicates that at the lowest altitude the " $A$ " model predicts significantly better fuel consumption than the "B" model, hence the low value of about $480 \mathrm{lb}$ fuel in figure 4.3 is probably not attainable. At high altitudes the reverse is true, however, as the " $\mathrm{A}$ " model does not fit the cruise data well in this range and predicts significantly better fuel consumption than the "B" model. Thus, while the trend predicted in figure 4.3 is correct the actual minimum fuel used is probably in error and the penalty for high crulse altitudes may be greater than that shown.

At the intermediate weight of $17,000 \mathrm{lb}$ the cruise cost of figure 2.7 shows little variation with altitudes for performance model "A." Similarly in figure 4.3 the total fuel consumed varies by only about $10 \mathrm{lb}$ for all cruise altitudes from 
$1,000 \mathrm{ft}$ to $12,000 \mathrm{ft}$. Thus, in this weight range there is little to be gained by optimizing cruise altitude (of course velocity must still be optimized!). In view of the differences between the " $A$ " and " $B$ " models at the high altitudes, conservative engineering judgment indicates that a cruise altitude below $8,000 \mathrm{ft}$ is probably appropriate.

The identical curves for a $100 \mathrm{n}$. mi. range mission are shown in figure 4.4 . While the behavior is similar, we observe that there is slightly more variation in the 17,000 $\mathrm{lb}$ case. The reason for this is that the cruise fuel is based on the average cruise welght. Thus, while the Initlal weights on figures 4.3 and 4.4 are the same, the "average cruise weight" for the $100 \mathrm{n}$. m1. range 1s almost $200 \mathrm{lb}$ less than in the former case. Note also that since the $\psi$ is different, the ascent and descent Hamiltonian is slightly different; therefore, the resulting climb and descent profiles are not exactly the same in the two cases. In general, a smaller, more favorable cruise parameter $\psi$ causes the ascent leg of the optimal trajectory to be steeper and to climb more quickly, making the climb segment shorter and the crulse segment longer.

\subsection{Speed Varlation on Optimal Trajectorles}

Optimal climb speeds on the minimum fuel trajectories tend to be much faster than the speeds for fastest climb rate (60-70 knots). At comparable altitudes the speed in descent is generally faster than the speed in climb. The variation of the optimal speeds for one particular weight is shown in figure 4.5 for varlous cruise altitudes. Numerical minimization of the Hamiltonian does confirm, in fact, that at the cruise altitude, the three speeds $V_{U P}, V_{D S T}$, and $V_{C R}$ all coalesce to a single value. The advantage of trading off climb rate for forward speed can be seen in table 4.1 which compares an optimal climb-cruise-descent profile with a fastest climb-optimal cruiseoptimal descent profile of the same total range. For the fastest climb rate, flight speeds are between 60 and 70 knots true airspeed.

While the advantage is slight, only about $2 \%$, it should be pointed out that the fuel consumed in this case is dominated by the long cruise. In a shorter-range trajectory, it is antitipcated that the relative advantage of the optimal profile will be increased.

Sensitivity of the speed profile to the helicopter performance model can be deduced by computing trafectories under different hypotheses. Thus, flgure 4.6 shows the effect of using the smoothed model (A) or the pointwise model (B). In this case the speed differences are less than 5 knots everywhere on the trajectory. Even less important in determining the climb velocity is the climb factor $k_{C L B}$. Figure 4.7 shows that the optimal speed is essentially independent of the climb factor for the case shown. The optimal trajectory will of course differ substantially. The lack of sensitivity to these model parameters is typical of the cases examined and seems to indicate that the optimal results presented here can be applied (judiciously as always) even if there exists some uncertainty regarding the correctness of the helicopter dynamic model.

\subsection{Effect of Winds}

The magnitude and direction of winds are known to have a substantlal effect on the optimal performance of any aircraft. This effect is accentuated on a conventional helicopter because of the low flight speeds which make even a moderate wind fairly important. The minimum fuel consumption for the 17,000-1b helicopter flying in 
$-20,0$, and +20 knot. wind is shown in figure 4.8 (negative values are headwinds, positive values are tallwinds). The effect of the wind on the fuel consumption is obviously an important factor, but it is perhaps more important to note that there is a substantial difference in the "optimal" fiight profile through such an environment. Figure 4.9 compares the optimal airspeeds on these same trajectories. A tailwind tends to decrease the optimal airspeed at all altitudes and to increase it for a headwind. This is in accord with the generally accepted effect of wind on the quasi-steady performance quantities. Wind variation with altitude is also easily handled by the optimization algorithm and again the altitude variation can have an important role in determining the optimal speed profile and the optimal altitude. Figures 4.10 and 4.11 show the fuel cost and the optimal climb speed for trajectories with various winds, Including a linear wind where the wind velocity varies from 20 knots at $h=0$ to 50 knots at $h=12,000 \mathrm{ft}$. While these winds are fairly substantial, they do represent, In fact, a typical environment for helicopters operating in off-shore areas. The winds are added into the trajectory logic with 1ittle or no increase in complexity. The main difficulty with incorporating winds into an on-line procedure is the problem of determining the actual wind profile in the area of flight. If such knowledge can be obtained, the potential payoff is substantial.

\subsection{General Cost Optimization}

The previous results have all applied to a direct fuel minimization. The general cost function specified in this analysis allows a welghting between time and fuel. This can be used to minimize a "dollar" cost if an appropriate cost of time and fuel is specified. In addition, by varying the weight factor on time $\left(c_{T}\right)$, the total flight time can be controlled. Determining an appropriate numerical value for $c_{F}$ is done by simply inspecting the cost of fuel. For standard JP-4 at $\$ 1.16 / g a 1$ at $6.5 \mathrm{lb} / \mathrm{gal}$, this leads to $c_{F}=\$ 0.18 / 1 \mathrm{~b}$. The time weight factor, $c_{T}$, is a more subtle number to select. While direct operating costs are generally quoted as $\$ 500-\$ 1,000 / \mathrm{hr}$, the cost savings due to a decreased time is probably less than this value.

Using $c_{F}=\$ 0.18 / 1 b$, the effect of $c_{T}$ on the time of flight and the fuel required is plotted as a function of the cruise altitude in figure 4.12. Even when $c_{T}=0$ (direct fuel minimization) the optimal speeds lie close to, or on, the $V_{N E}$ boundary (compare the $V_{N E}$ profiles shown in figure 2.8 to the speed profiles as in figures 4.9 and 4.11). The sudden slope discontinuity, at $h_{C R} \cong 8,000 \mathrm{ft}$ in $\mathrm{fig}-$ ure 4.12 on the $c_{T}=0$ curve indicates the point where the optimal cruise speeds are being pushed back by the receding $V_{\mathrm{NE}}$ boundary, thereby increasing the time of flight. By making $c_{T}$ positive, optimal speeds are increased. When $c_{T}$ reaches $\$ 100 / h r$, the "optimal" speed is simply $V_{\mathrm{NE}}$ at all points on the trajectory independent of the cruise altitude chosen. In this case, the minimum flight time occurs at about a cruise altitude of $5,000 \mathrm{ft}$, where the maximum $V_{N E}$ (for this weight) occurs. If the cruise altitude is fixed, increasing $c_{T}$ beyond $\$ 100 / h r$ cannot change the trajectory since the velocity is already at a constraint boundary. It will change the "cost" certainly and will change the "optimum" cruise altitude - with larger values of $c_{T}$ causing the optimal cruise altitude to drop to the minimum time altitude.

The appropriate values of $c_{T}, c_{F}$ to use in a realistic environment must be determined by the helicopter operator. For this example, with a fixed $50 \mathrm{n}$. mi. range, the minimum-fuel trajectory cruises at $12,000 \mathrm{ft}$ and uses $375 \mathrm{lb}$ fuel with a flight duration of $0.45 \mathrm{hr}$, or $2 \% \mathrm{~min}$. For the minimum-time trajectory, on the other 
hand, the cruise is at 5,000 ft, the total trip time is about $5 \mathrm{~m} 1 \mathrm{n}$ shorter, and the fuel consumed is an extra $100 \mathrm{lb}$.

\section{CONCLUDING REMARKS}

The on-line determination of optimal flightpaths for helicopters has been shown to be useful and computationally feasible. The two developments which permit the solution to this problem are: (I) an efficient, simple performance model for the helicopter and (2) use of the simplifled "climb-cruise-descent," trafectoryoptimization model.

To ensure the accuracy requirement for the helicopter performance model it seems mandatory that the analytical model be empirically curve-fitted to the flighttest data. The model used in this report is based on a simple power model fit for varlous altitudes and welghts. For more general studies, a more refined model would be desirable and should probably be based on a parameterization in terms of more fundamental performance variables such as thrust coefficient and advance ratio. Nevertheless, for the specific vehicle under consideration, the optimal trajectories as computed are believed to be quite realistic. The primary characteristics of the optimal trajectories can be summarized as follows:

1. The speeds on fuel optimal trajectories tend to be fairly fast, that is, near the maximum speed of the vehicle. Speeds on the climb leg of the optimal trajectories tend to be significantly faster than the speed for greatest climb rate. As the length of the cruise segment increases, the optimal climb speed does, however, tend to approach that for greatest rate of climb. For many cases, particularly at high altitudes, the optimal climb speeds are limited by the $V_{N E}$ boundary of the aircraft. This situation and the fact that much of the flight manual power required data are also outside the $V_{N E}$ boundary seems quite unusual. If the quoted $V_{N E}$ boundary can reasonably be extended some improvement in performance could be achieved.

2. In contrast to the fixed-wing aircraft, all optimal helicopter trajectories have a nonzero cruise segment because of the nonunity climb factor used in the performance model. The cruise segment distance tends to be relatively constant at a small value until the cruise altitude approaches the altitude for minimum cruise cost at which point the cruise segment is determined by the range constraint. In practice the optimal altitudes are at sea level for the heavy weight case $(W \geq 17,0001 \mathrm{~b})$ and at $12,000 \mathrm{ft}$ (the maximum altitude) for low weights ( $\leqslant 15,000 \mathrm{lb})$. For the intermediate weights $(16,000 \cong 17,000 \mathrm{lb})$ the optimal altitudes change from the minimum to the maximum value. The difference in fuel consumed for all cruise altitudes is slight, however, in this weight range and in view of uncertainty associated with the high altitude performance model for this weight, the low to intermediate cruise altitude should be chosen.

3. The descent segment of the trajectory is always flown on a minfmum power constraint of some type. While the fuel consumed in the descent segment is generally much less than on the remainder of the trajectory (hence, fuel optimization is much less critical), the descent range is crucial in determining the length of the remaining trajectory segments. A primary consideration in establishing any descent criteria is to avoid autorotation and the vortex ring state. The constraint used almost exclusively in this report was a fixed descent rate of $1,800 \mathrm{ft} / \mathrm{min}$. This figure was judged reasonable for VFR trajectorles based on conversations with several helicopter pilots. Depending on weather and proximity to the ground, lower descent rates 
could be imposed. It should be noted that optimum flight speeds are Independent of the particular descent rate chosen:

Because the descent range is crucial in determining the length of the other trajectory segments, additional input is needed, particularly from pilots, to determine what type of descent criteria is most appropriate for elther manual or automatic flightpath control.

4. Substantial decreases in time of flight can be achieved with only a small fuel penalty. Generally, the weighting of time on the optimal trajectory tends to force the cruise alt1tudes toward the altitude for greatest true airspeed - about 5,000 ft for this vehicle (the exact altitude depends on weight). Speeds in this case are generally on a $\mathrm{V}_{\mathrm{NE}}$ boundary.

Further work needs to be performed to improve and/or validate the performance model used in this report. This should include more detalled analytical modeling as weil as flight-test verification." Topics for further study include: (1) trajectory integration with the takeoff and landing phases of vehicle operation, (2) integration of the optimal trajectory system with 3-D and 4-D flightpath guldance. systems, and (3) more rigorous comparison of the optimal trajectories with the results of an unconstrained optimization. 
1. Schmitz, F. H.: Optimal Takeoff Trajectorles of a Heavily Loaded Helicopter. J. of Aircraft, vo1. 8, no. 9, 1971, pp. 717-723.

2. Schmitz, F. H.; and Vause, C. R.: A Simple, Near-Optimal Takeoff Control Policy for a Heavily Loaded Helicopter Operating From a Restricted Area. AIAA Paper 74-812, Aug. 1974.

3. 01sen, J.: Helicopter Mission Optimization Study. NASA CR SER-50998, June 1978:

4. F1ight Manual, S-61N Helicopter, Sikorsky Aircraft Pub. no. SA 4045-82.

5. Bramwe11, A. R. S.: Helicopter Dynamics. W1ley \& Sons, Inc., New York, 1976.

6. Gessow, A.; and Myers, G. C.: Aerodynamics of the Helicopter. Ungar Publishing Co., 1952 (Repub1ished, 1967).

7. Keys, C. N.: Rotary Wing Aerodynamics. Vo1. II, Performance Prediction of Helicopters. NASA CR 3083, Jan. 1979.

8. Bryson, A. E.; and Ho, Y. C.: Applied Optimal Control. Wiley \& Sons, Inc., 1975.

9. Erzberger, H.; and Lee, H.: Constrained Optimal Trajectories with Specified Range. J. Guidance and Control, vol. 3, no. 1, 1980, pp. 78-85. 
TABLE 2.1.- S-61N HELICOPTER COEFFICIENTS

\begin{tabular}{|ll|}
\hline $\mathrm{A}$ - rotor area & $3019 \mathrm{ft}^{2}$ \\
$\sigma$ - solidity & 0.077 \\
$c_{d}$ - average drag coefficient & 0.010 \\
$\mathrm{f}_{e}$ - drag area & $30 \mathrm{ft}^{2}$ \\
$\mathrm{v}_{t}$ - rotor tip speed & $659 \mathrm{ft} / \mathrm{sec}$
\end{tabular}

TABLE 4.1.-

\begin{tabular}{|l|c|c|}
\hline \multicolumn{1}{|c|}{ Condition } & Optimal & Best R/C (ascent) \\
\hline Range up & 11.5 & 5.5 \\
Range cruise & 75.4 & $91.4 \quad$ \\
Range déscent & 13.1 & 13.1 \\
Total range & 100.0 & 100.0 \\
Fuel up & 145 & 117 \\
Fuel cruíse & 511 & 553 \\
Fuel descent & $\frac{60}{716}$ & $\underline{60}$ \\
Total fue1 & 730 \\
\hline
\end{tabular}



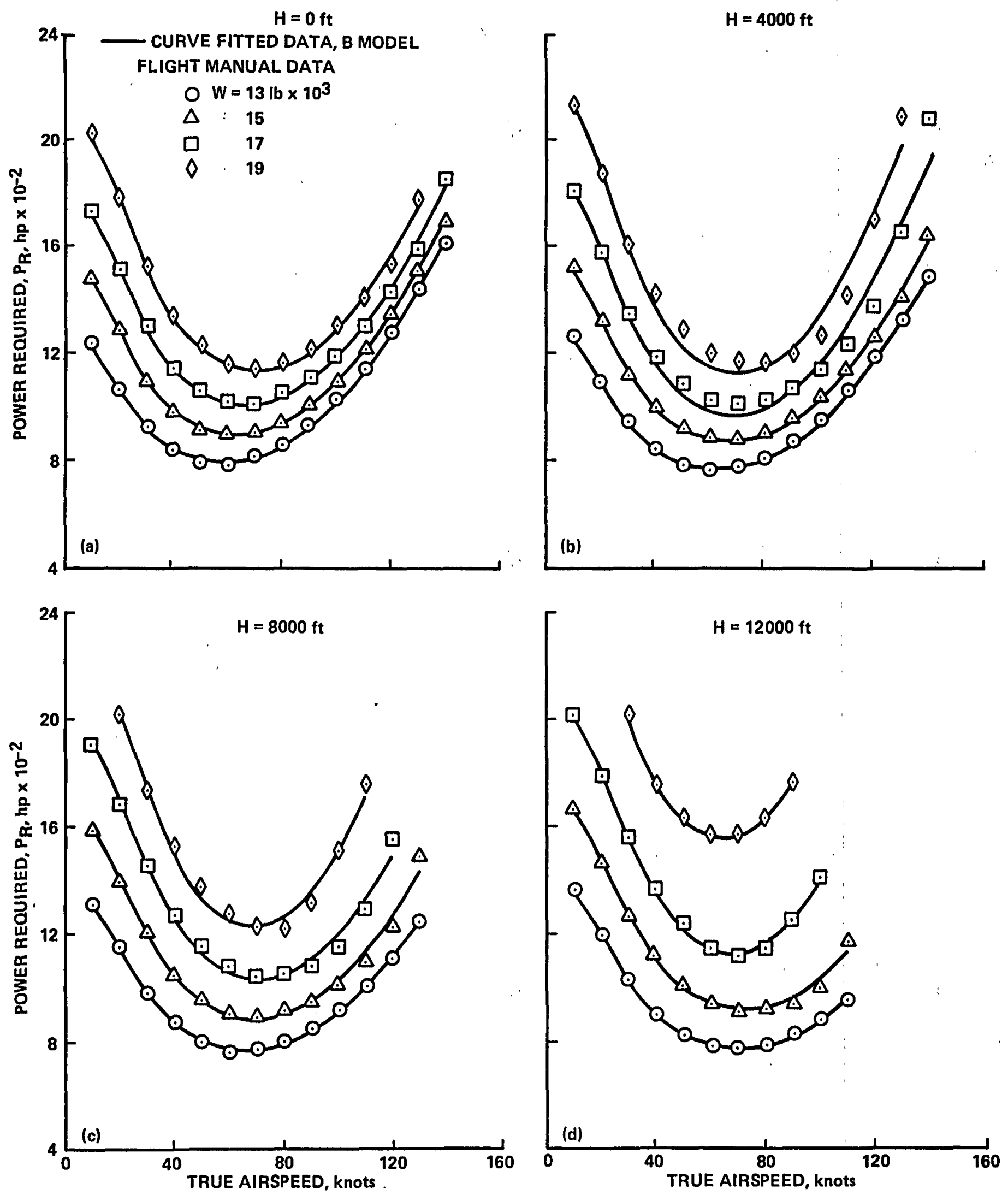

Figure 2.1.- Performance model fit at each weight and altitude. 


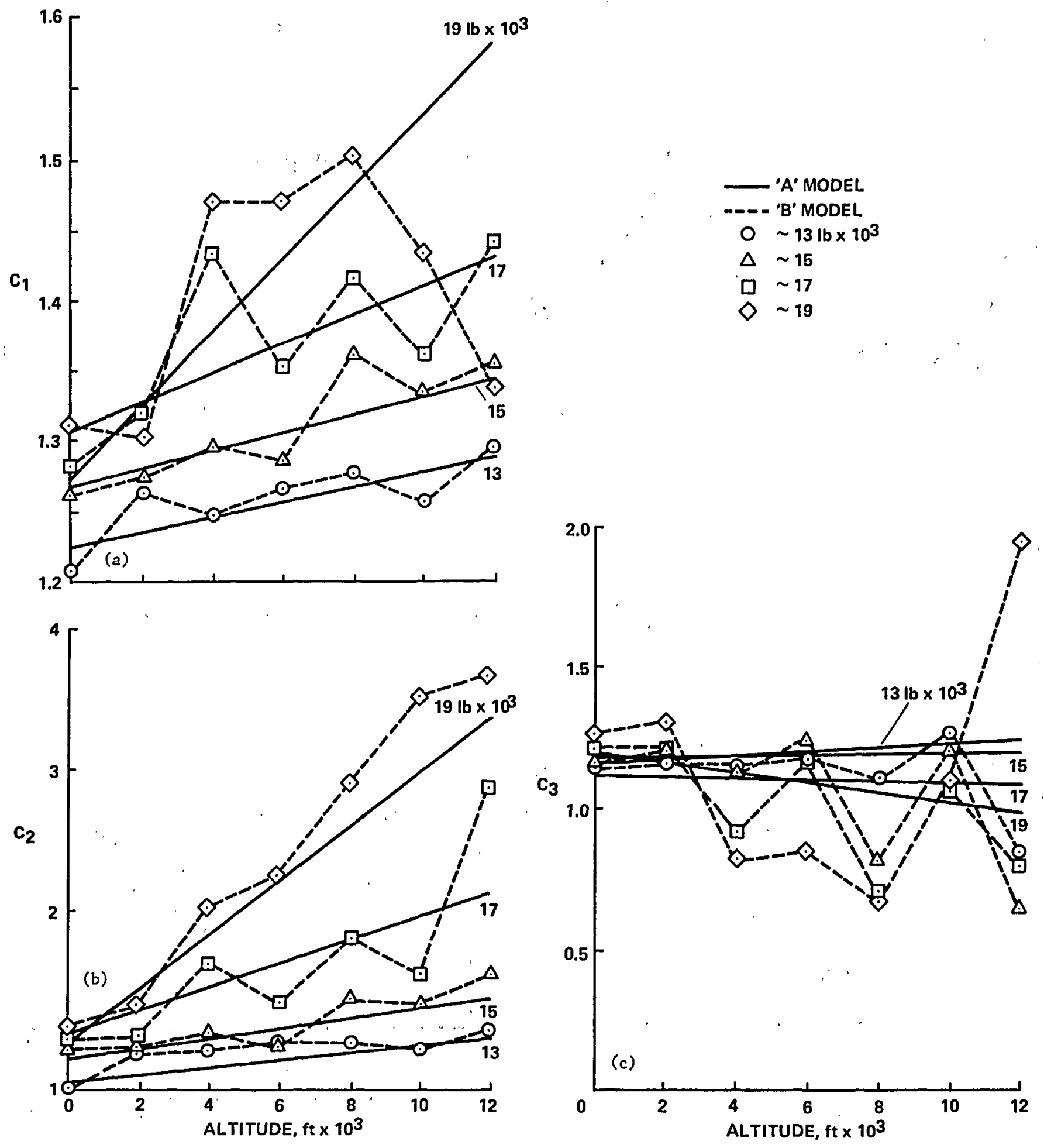

Figure 2.2- Variation of Power multiplier. (a) Induced; (b) Parasite;

$\because$ (c) Rotor profile. 

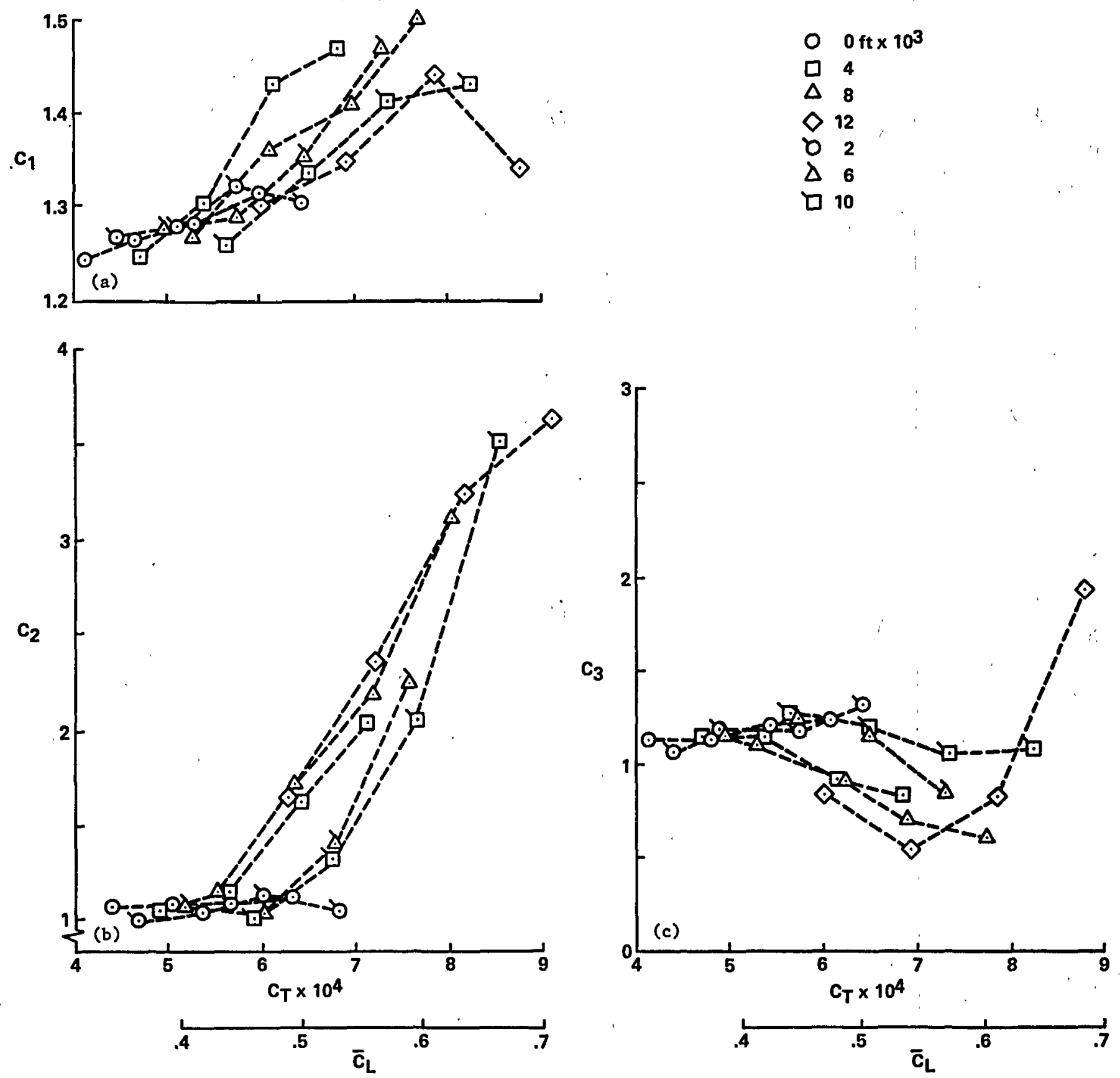

Figure 2.3.- Varlation of power multiplier with thrust coefficlent. (a) Induced; (b) Parasite; (c) Rotor profile. 

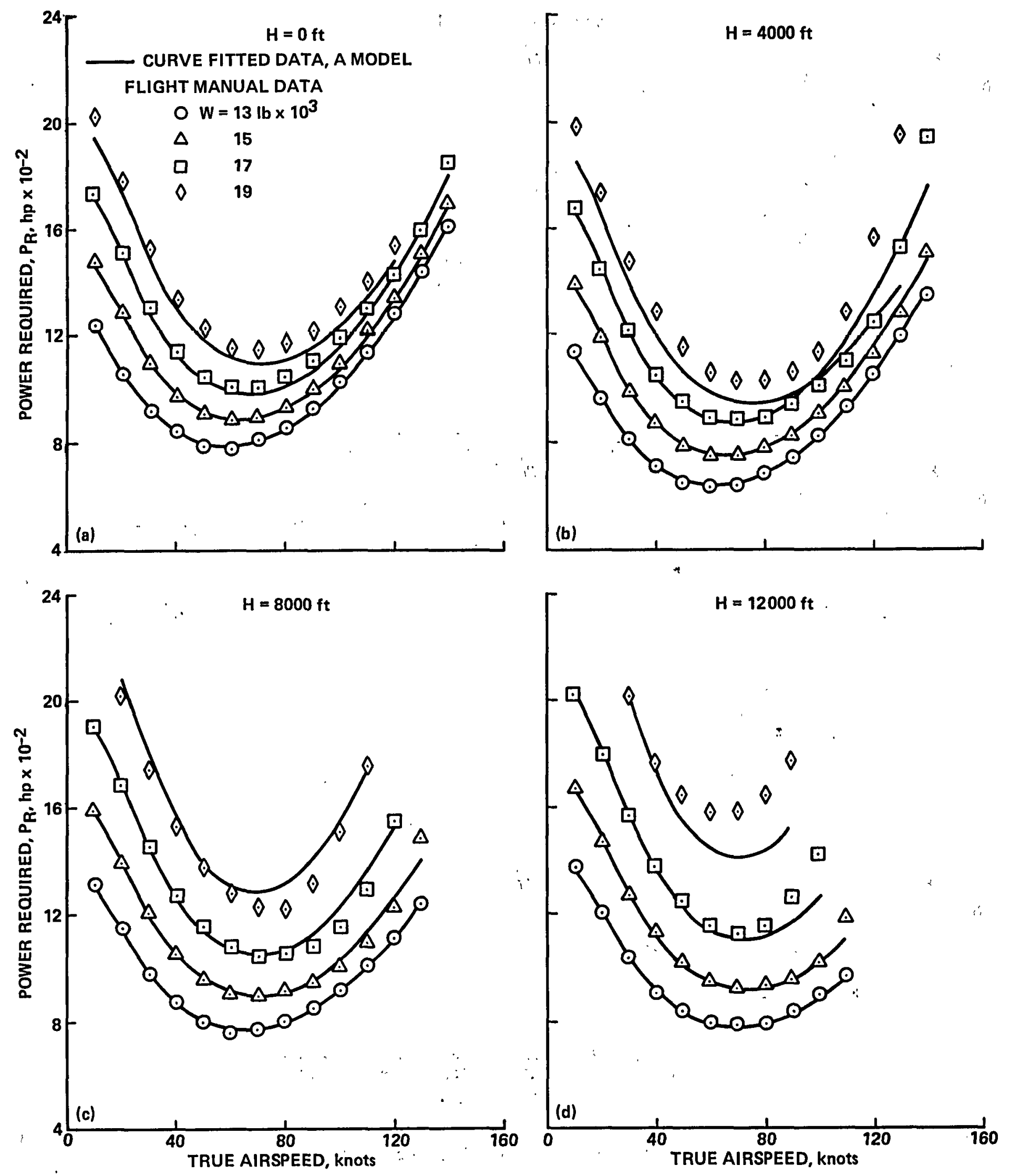

Figure 2.4.- Performance model fit as linear function of altitude. 


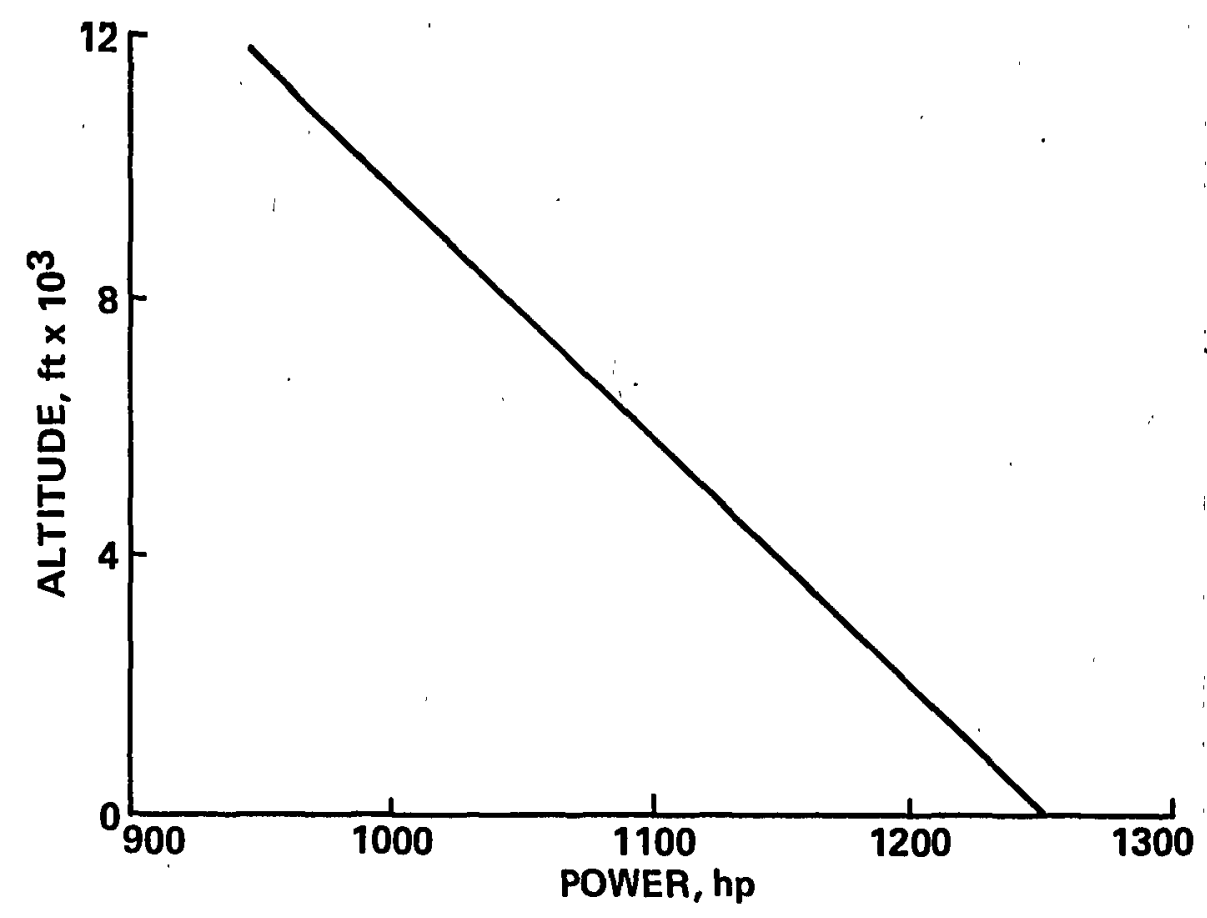

Figure 2.5.- Maximum power available for S-61N helicopter 2CT58-140 engines; standard atmosphere.

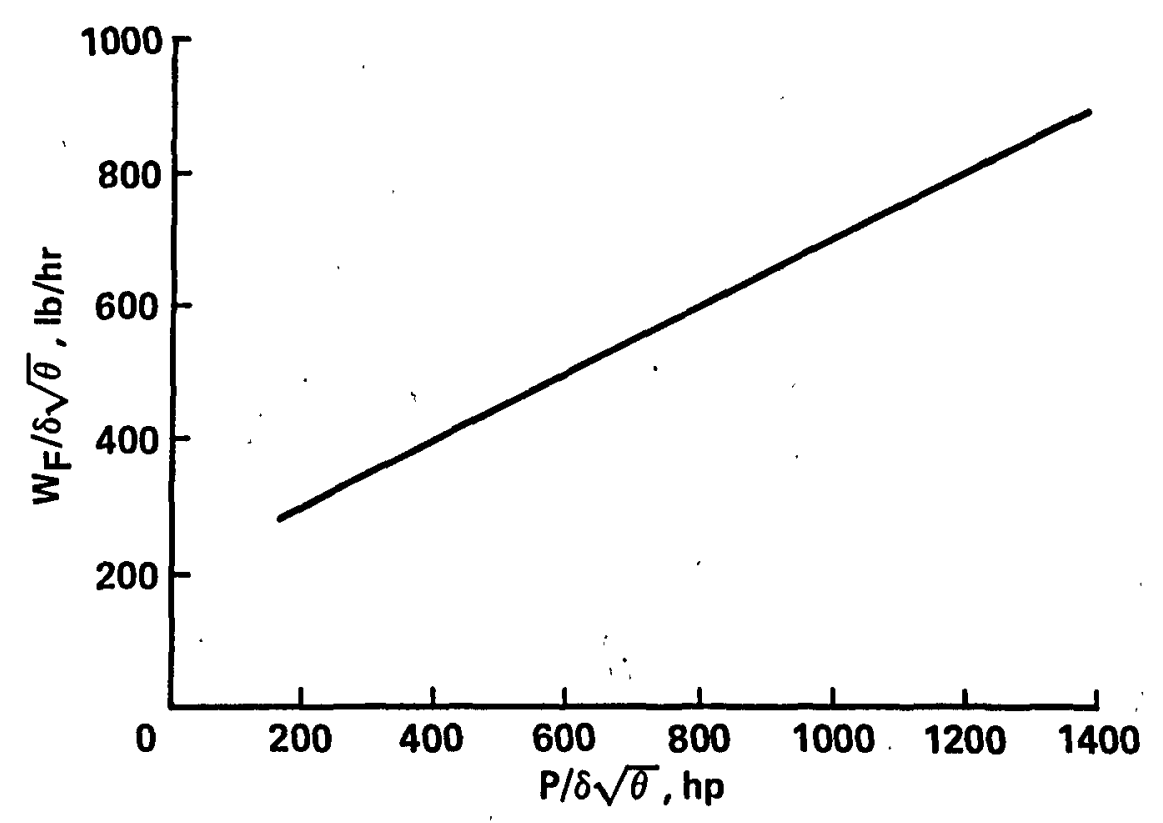

Figure 2.6.- Normalized fuel flow per engine (CT58-140). 


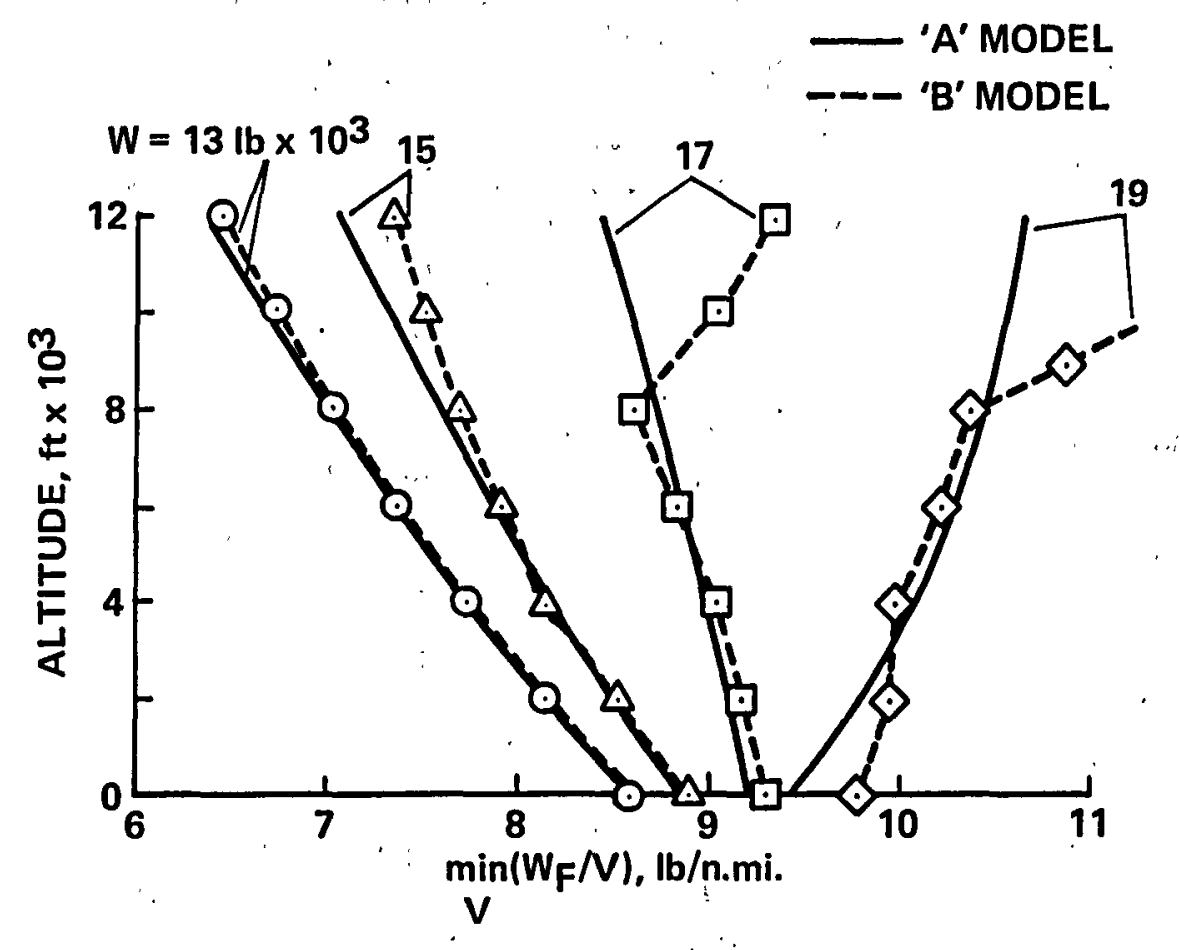

Figure 2.7.- Minimum fuel cruise cost for two performance models. 


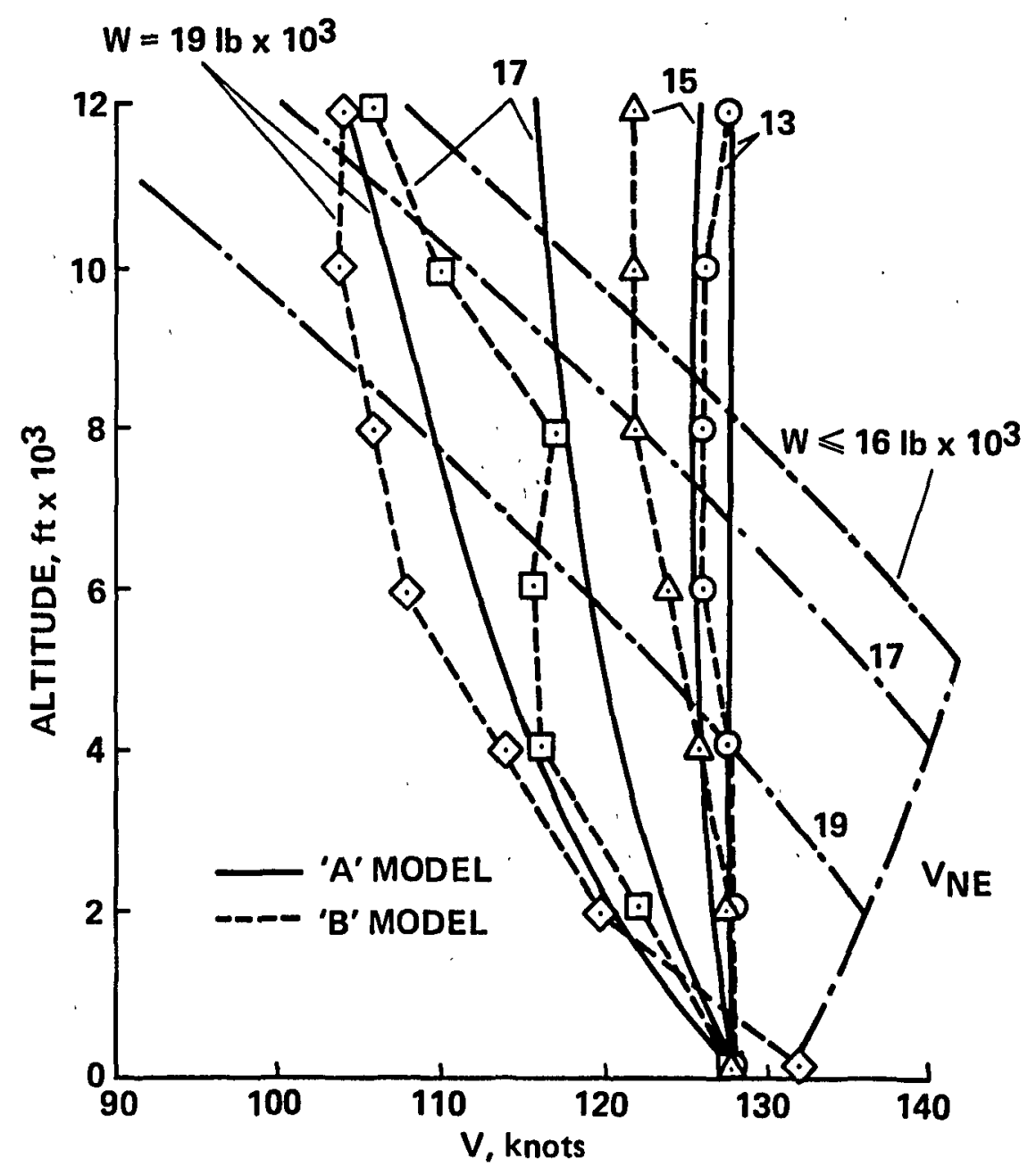

Figure 2.8.- Cruise speed for a minimum fuel cost. 


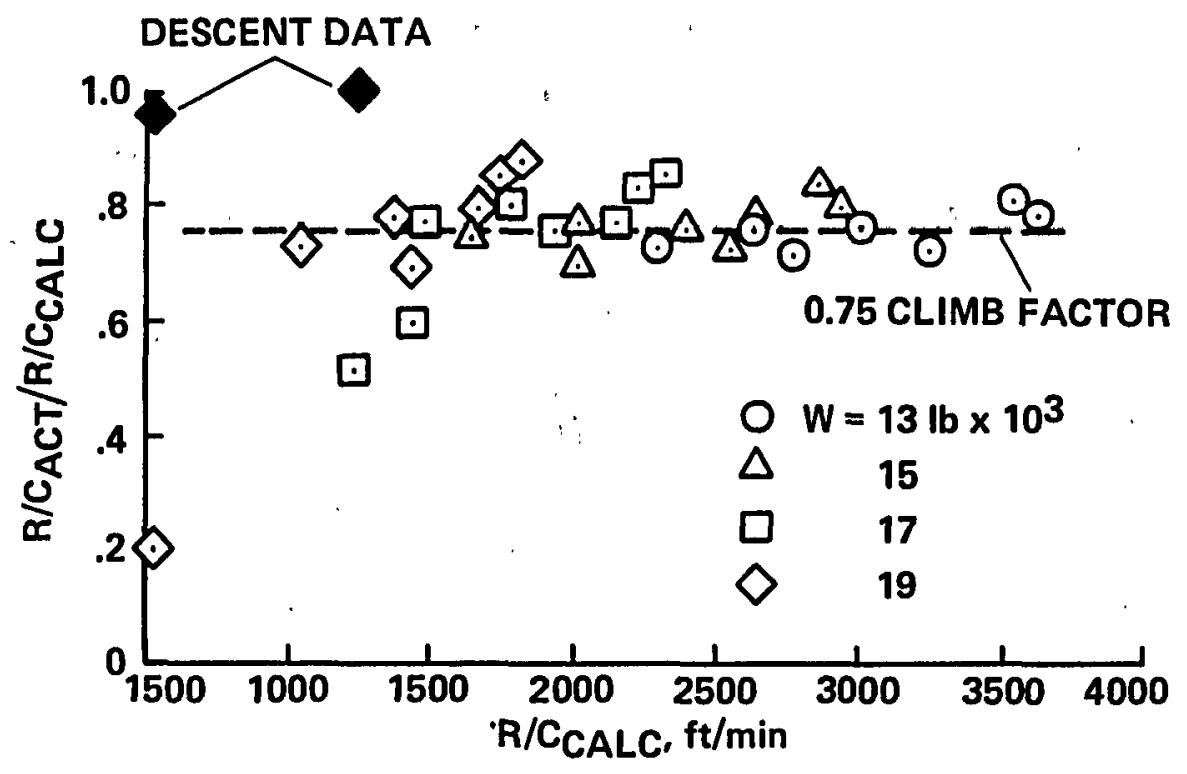

Figure 2.9.- Determination of climb and descent factors from flight manual data. 


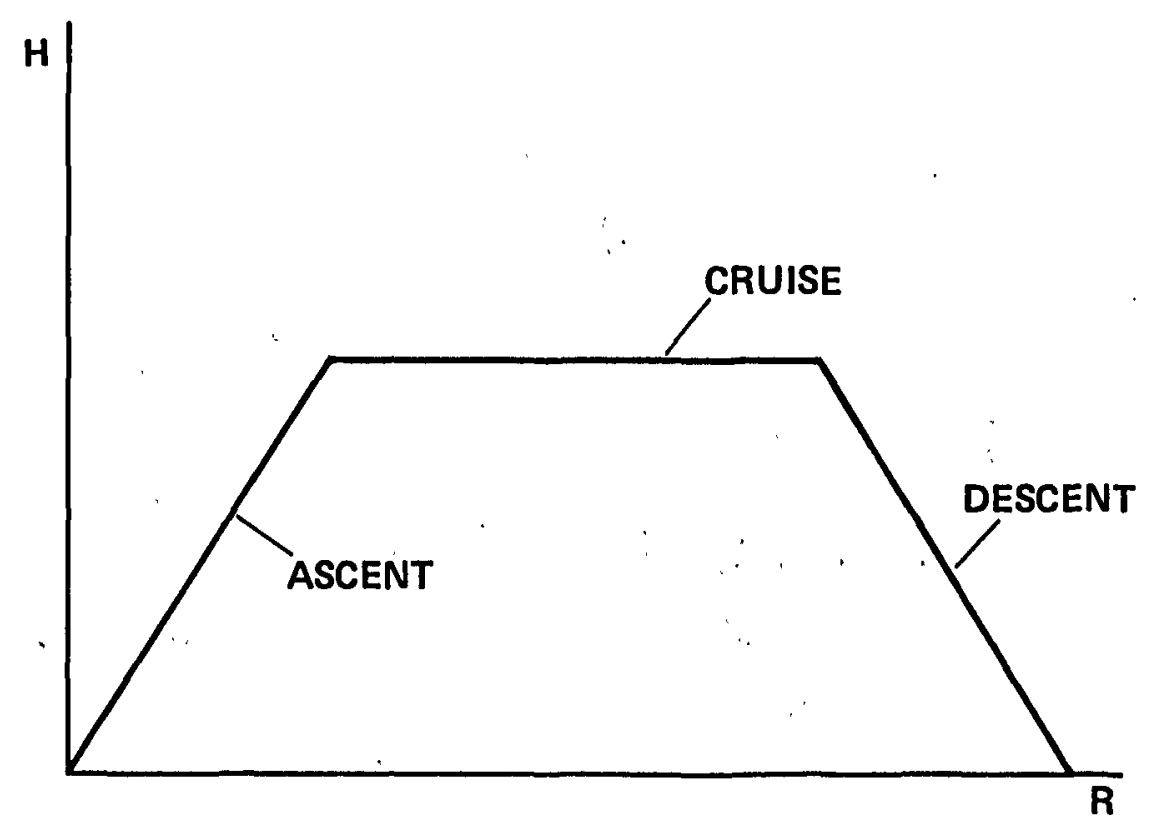

Figure 3.1:- Assumed structure of optimal trajectory.

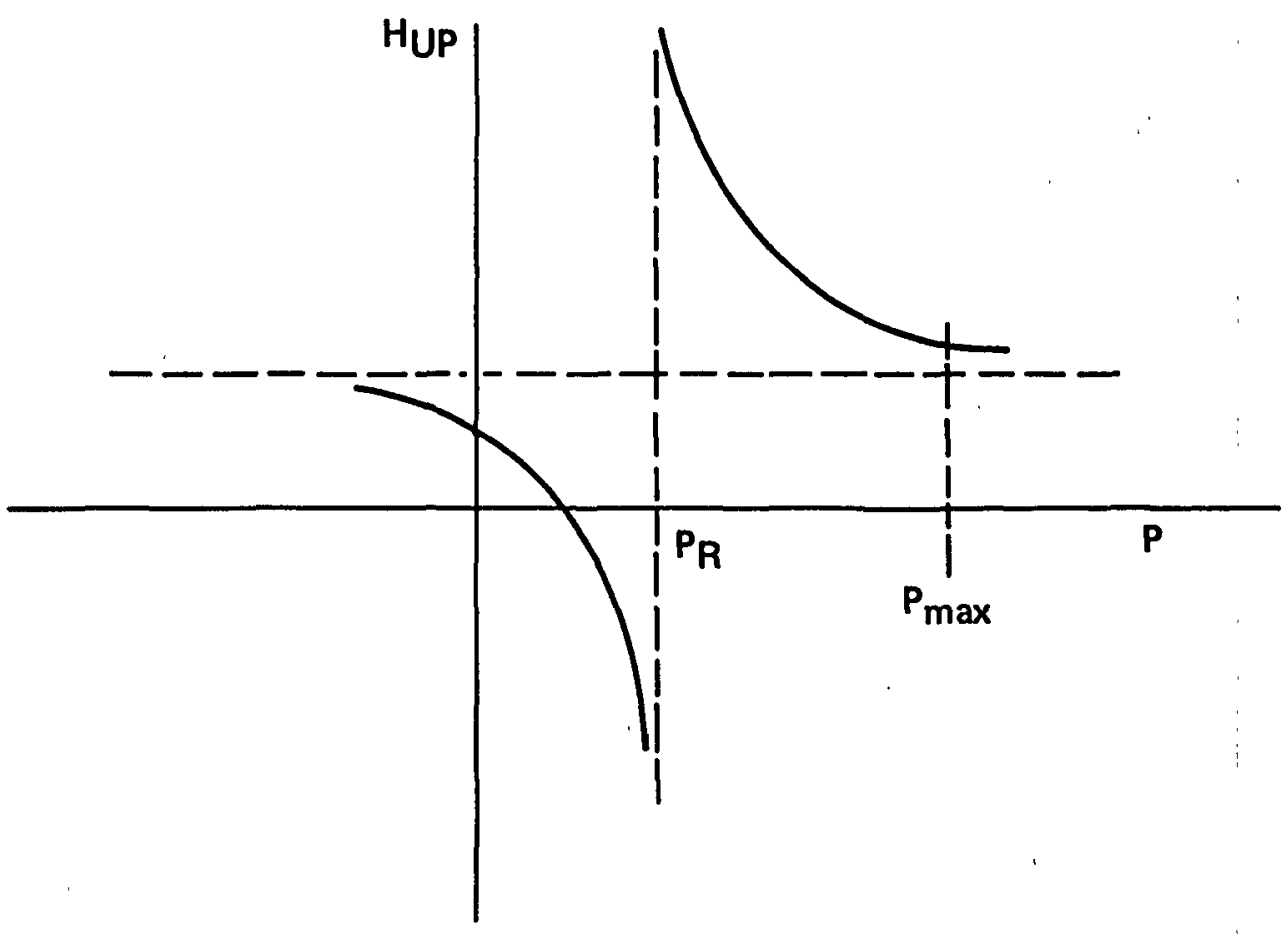

Figure 3.2.- Variation of $\mathrm{H}_{U P}$ with $\mathrm{P}$ for fixed $V$. 


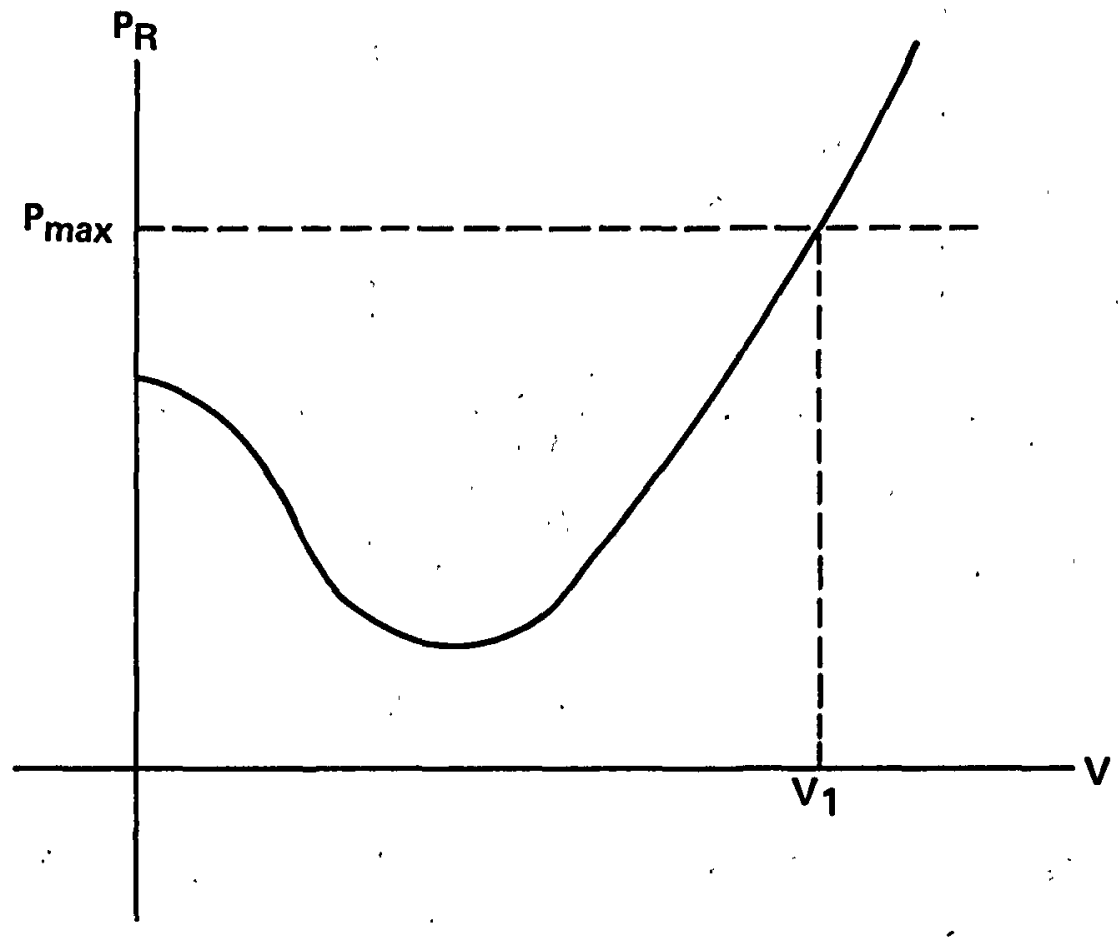

F1gure 3.3.- Typical variation of required power $P_{R}$.
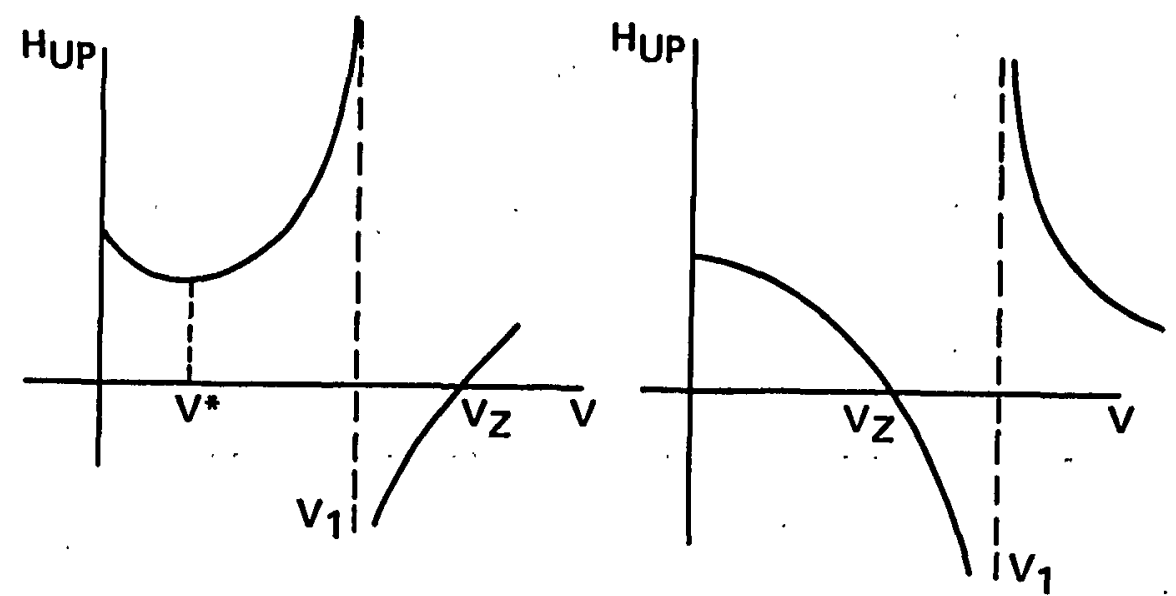

(a) $\dot{v}_{Z}>v_{1}$

(b) $v_{2}<v_{1}$

Figure 3.4.- Variation of $\mathrm{H}_{\mathrm{UP}}$ with $\mathrm{V}: \mathrm{V}_{1}$ limit. 


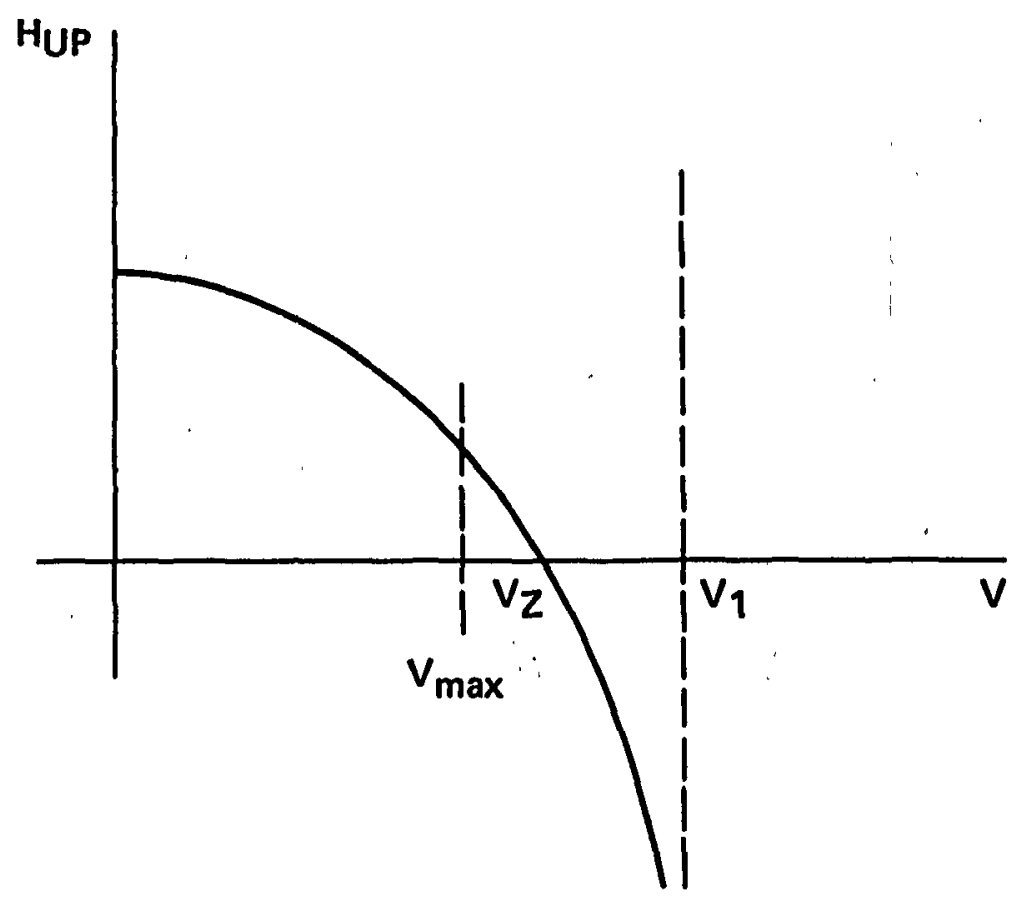

Figure 3.5.- Variation of $\mathrm{H}_{U P}$ with $\mathrm{V}: \mathrm{V}_{\max } 1$ imit.

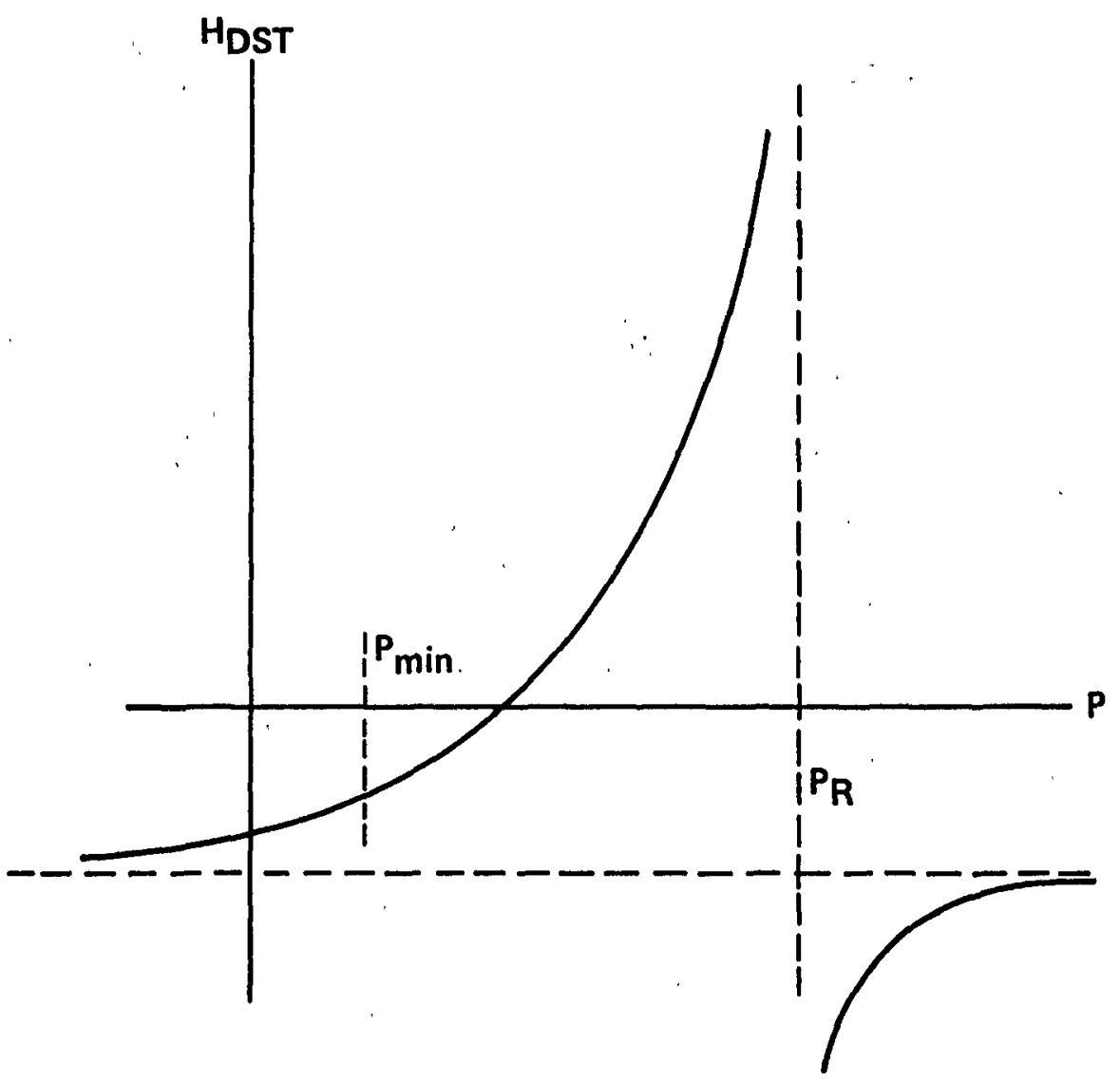

FIgure 3.6.- Variation of $\mathrm{H}_{D S T}$ with $P$. 


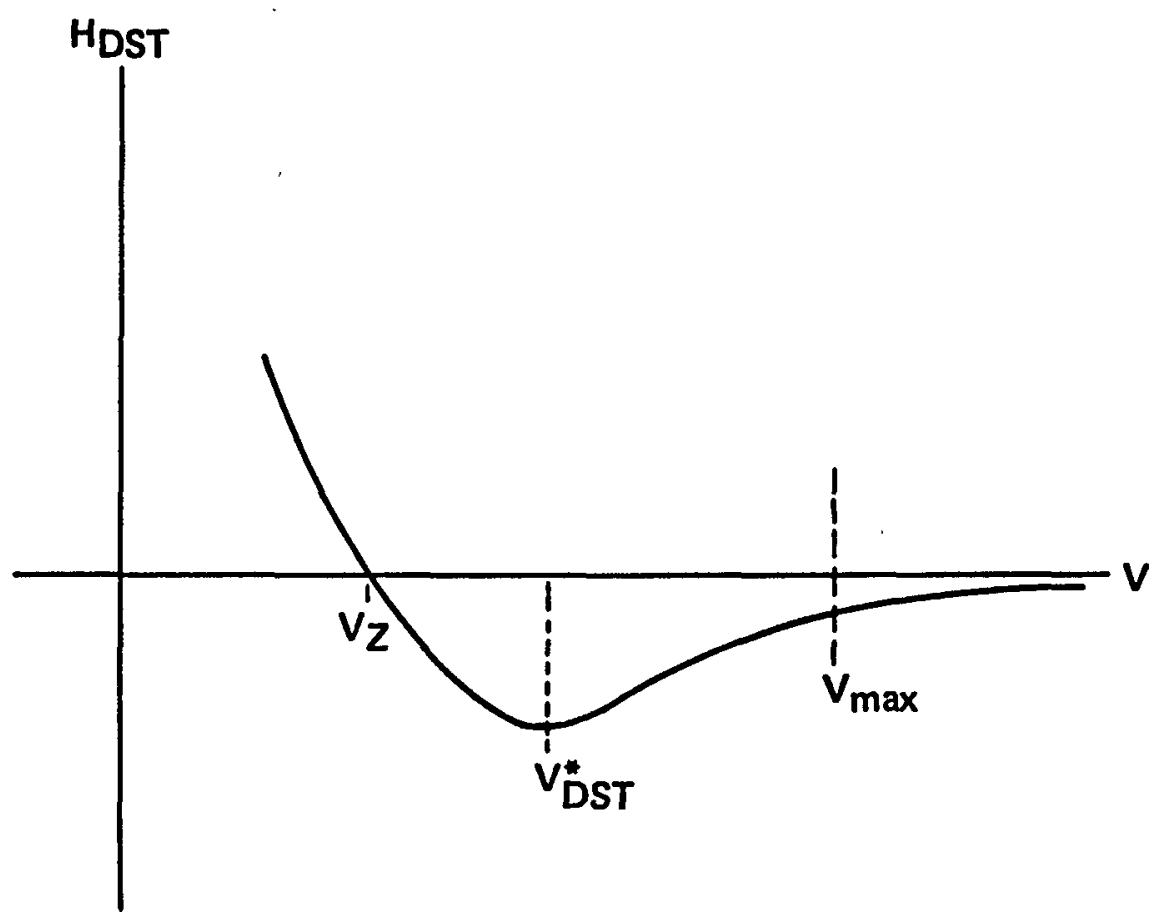

Figure 3.7.- Variation of $\mathrm{H}_{\mathrm{DST}}$ with $\mathrm{V}$. 


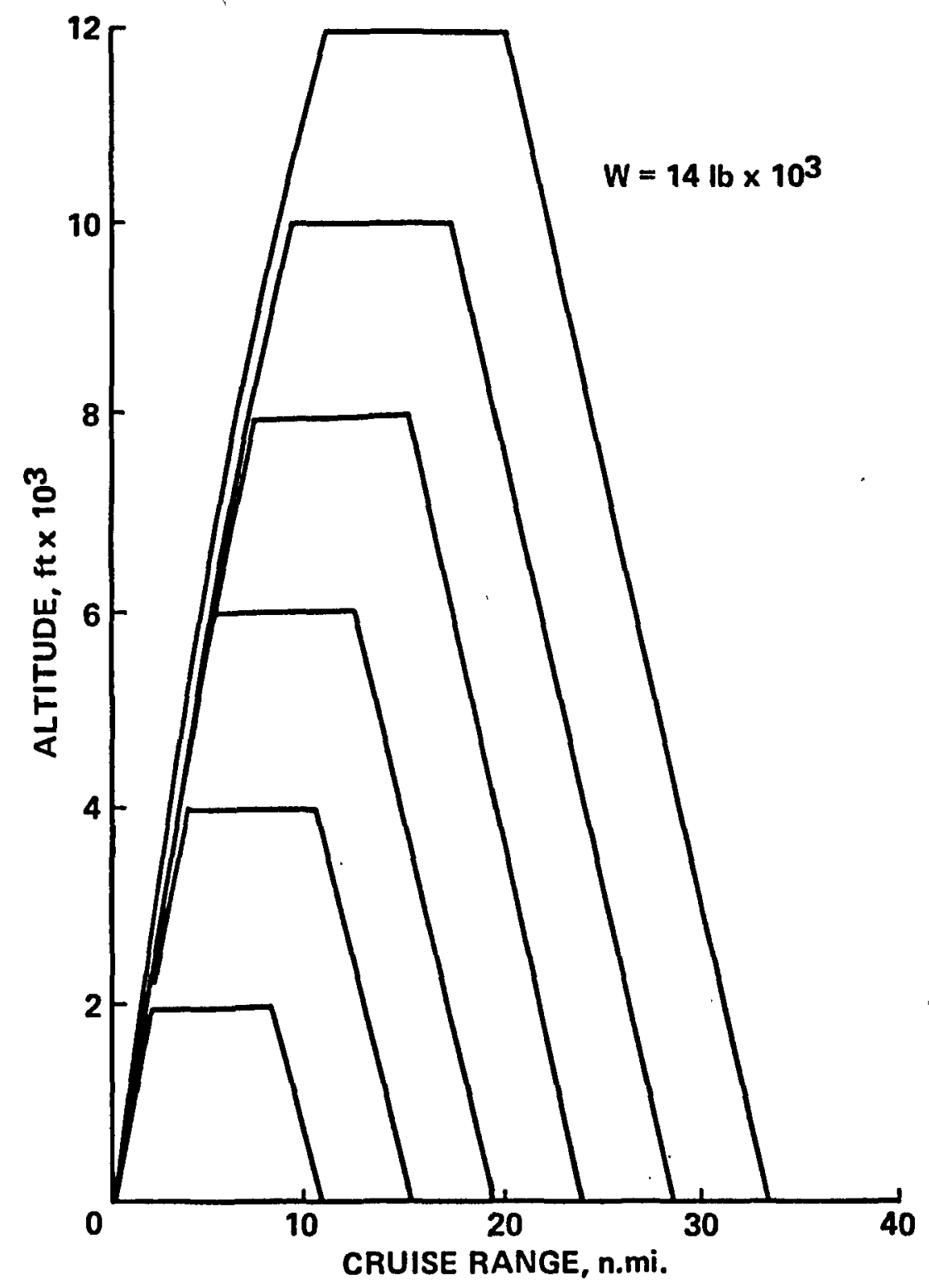

Figure 4.1.- Optimal trajectories using optimal cruise altitude. 

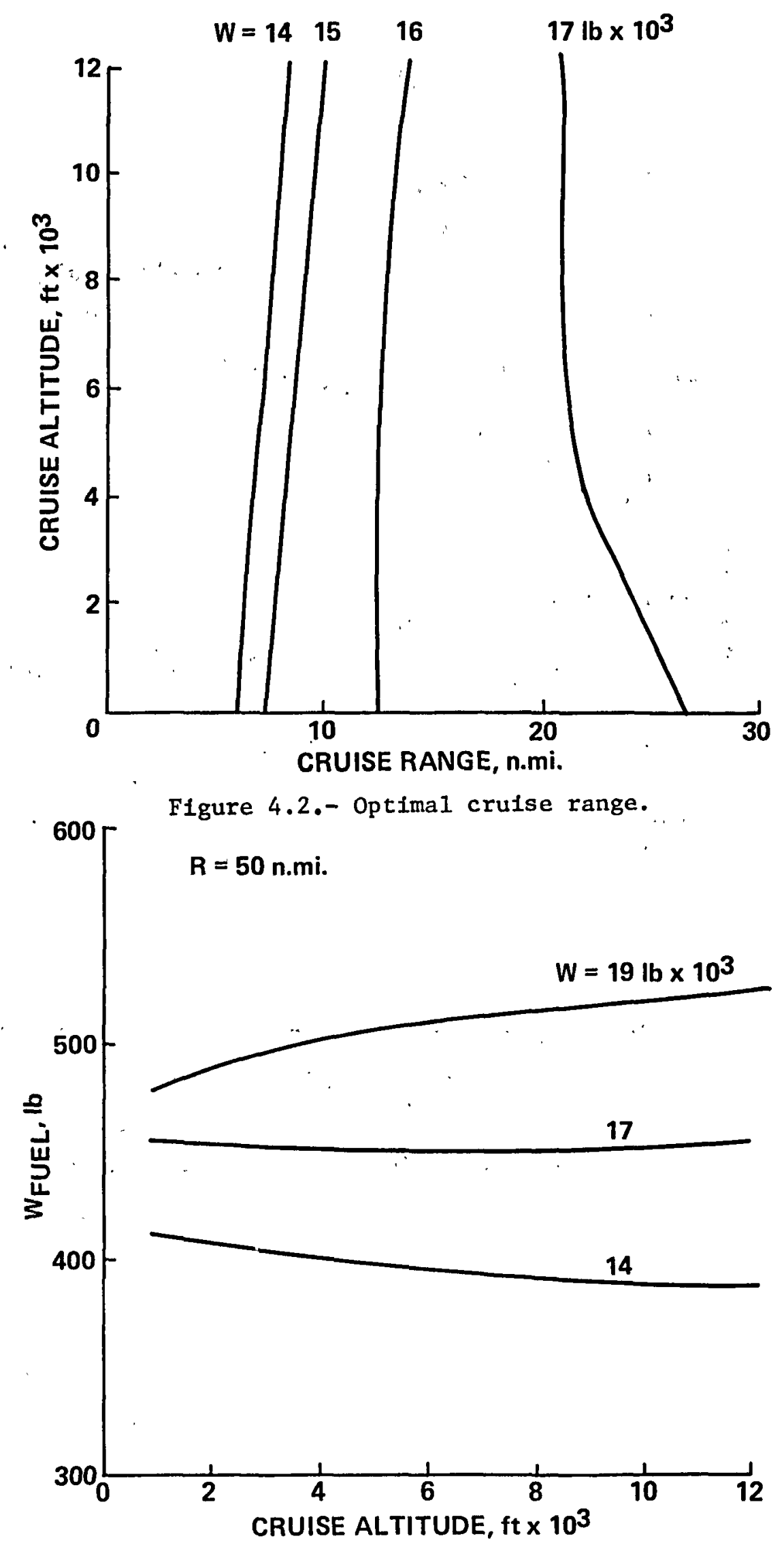

Figure 4.3.- Minimum fuel for $50 \mathrm{n}$. mi. trajectory for various cruise altitudes. 


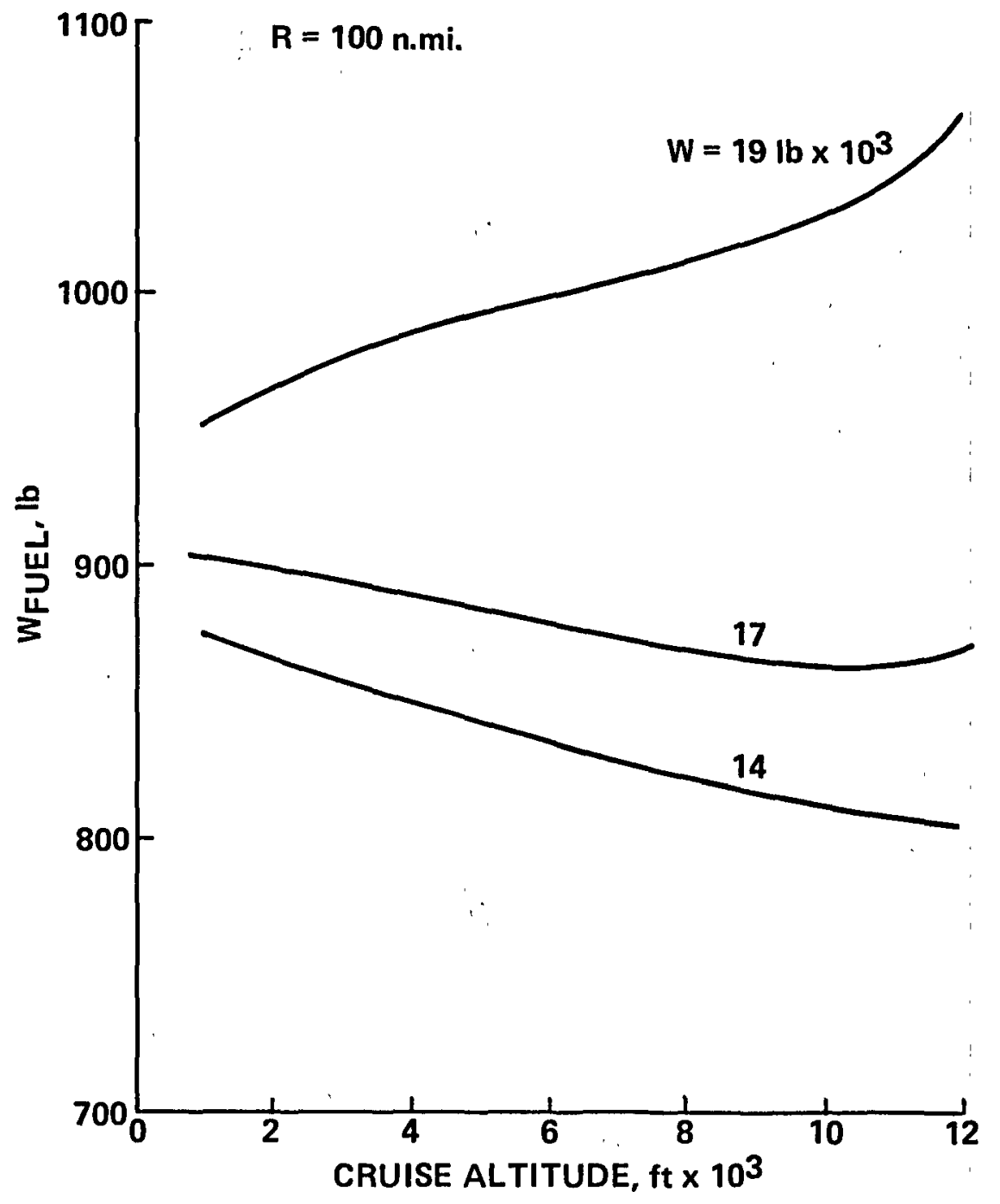

Figure 4.4.- Minimum fuel for $100 \mathrm{n}$. mi. trajectory for various cruise altitudes. 


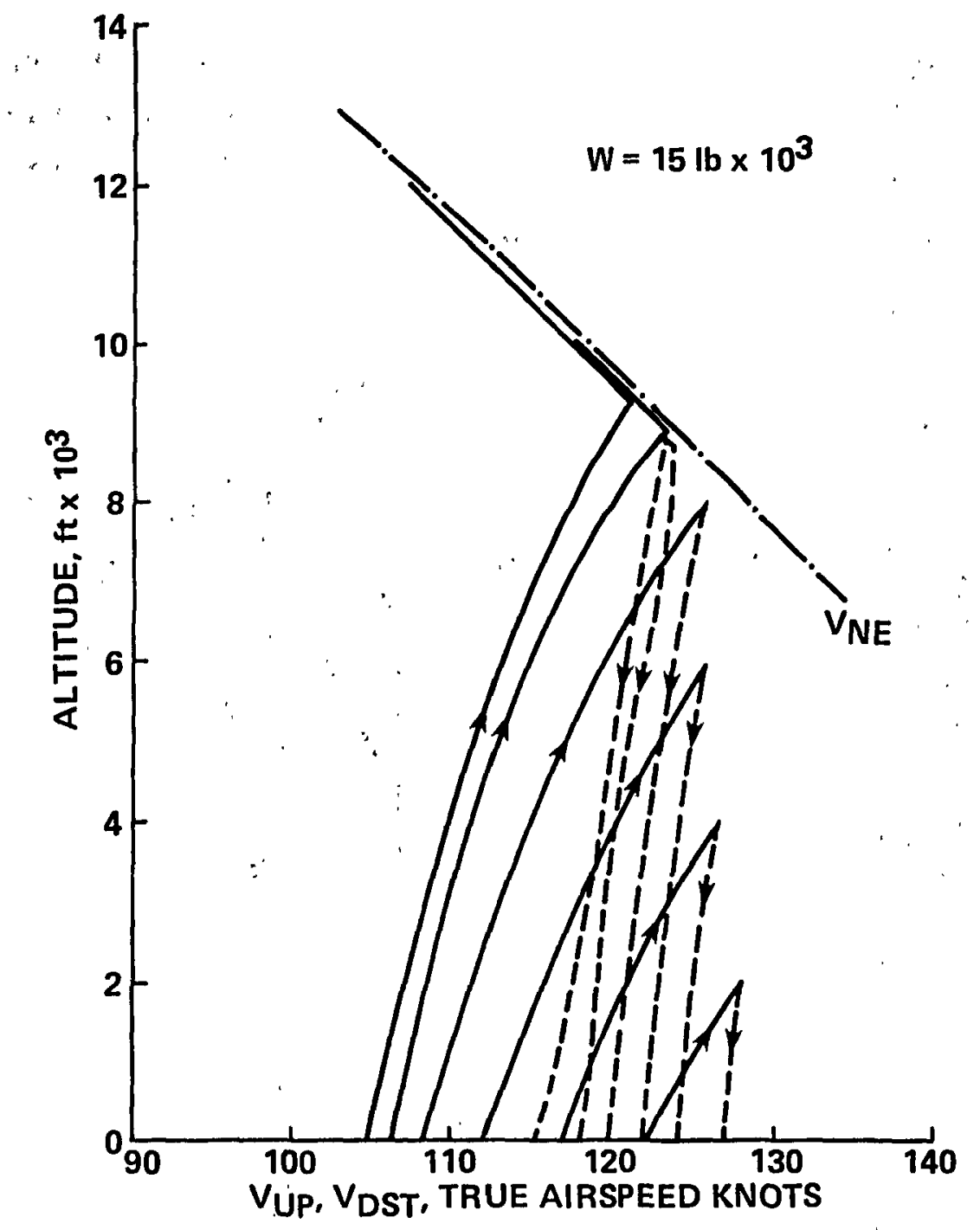

Figure 4.5.- Optima1 ascent and descent speeds as a function of altitude. 


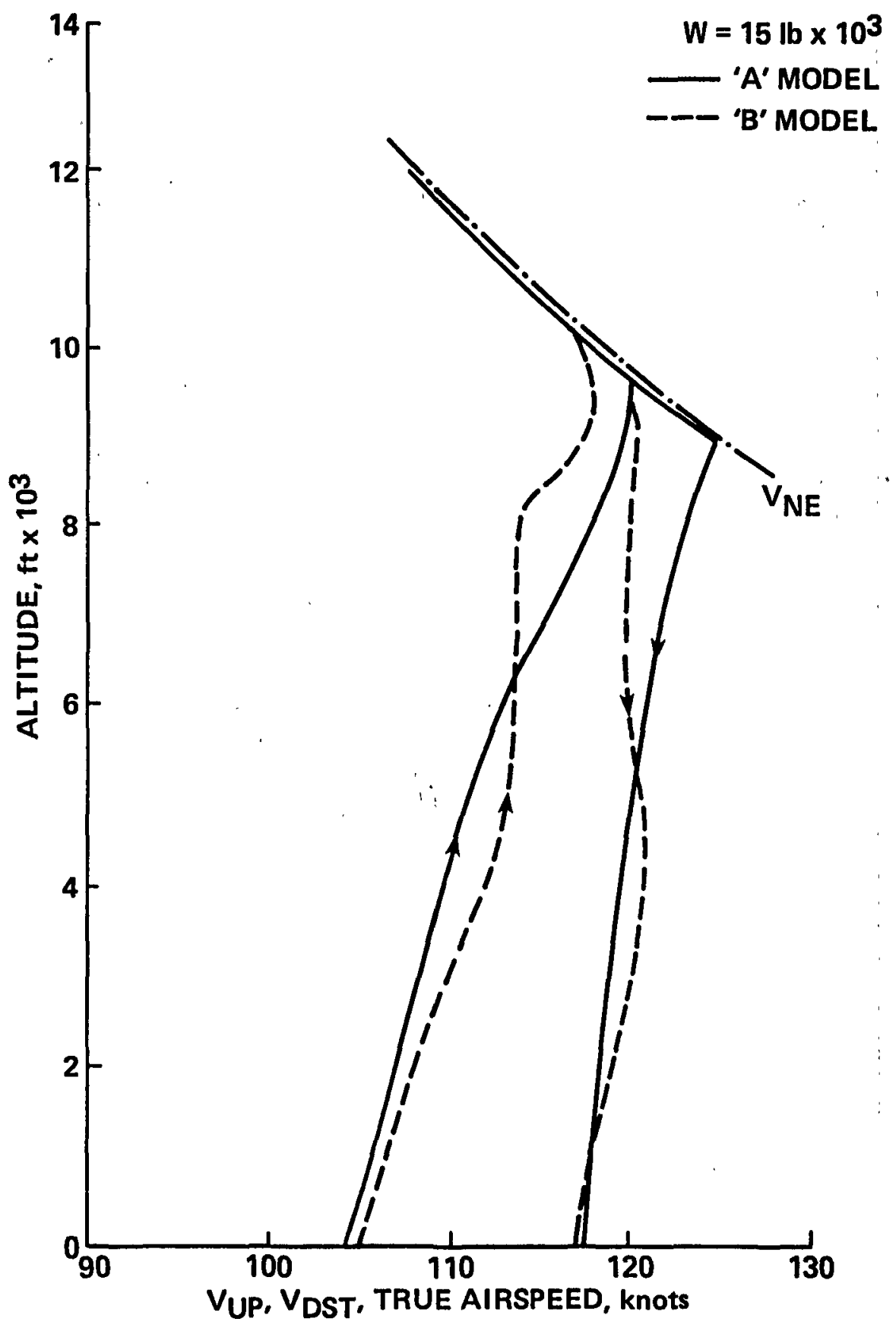

Figure 4.6.- Optimal ascent and descent speeds for two performance models.: 


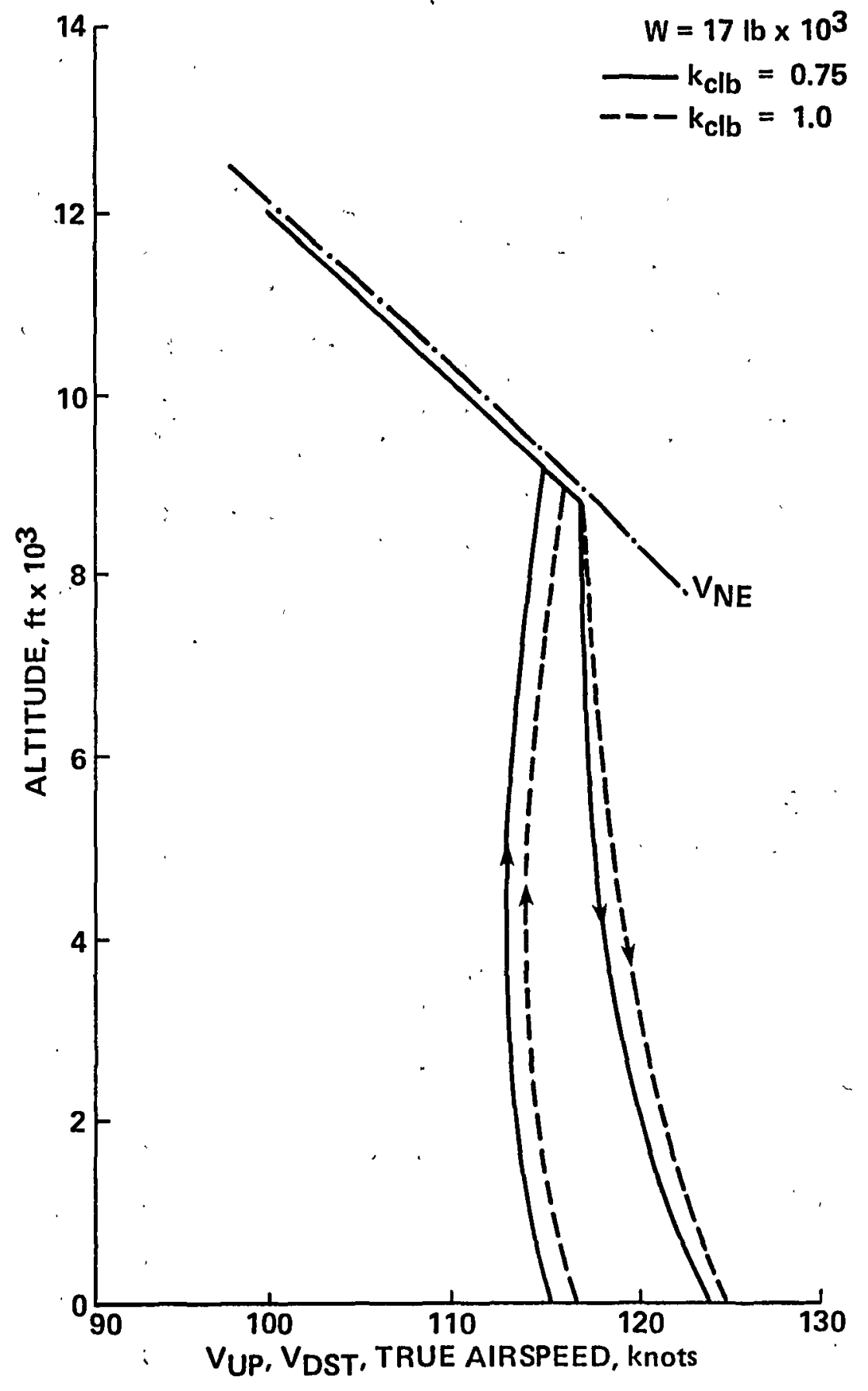

Figure 4.7.- Effect of $k_{c l b}$ on optimal ascent and descent speeds. 


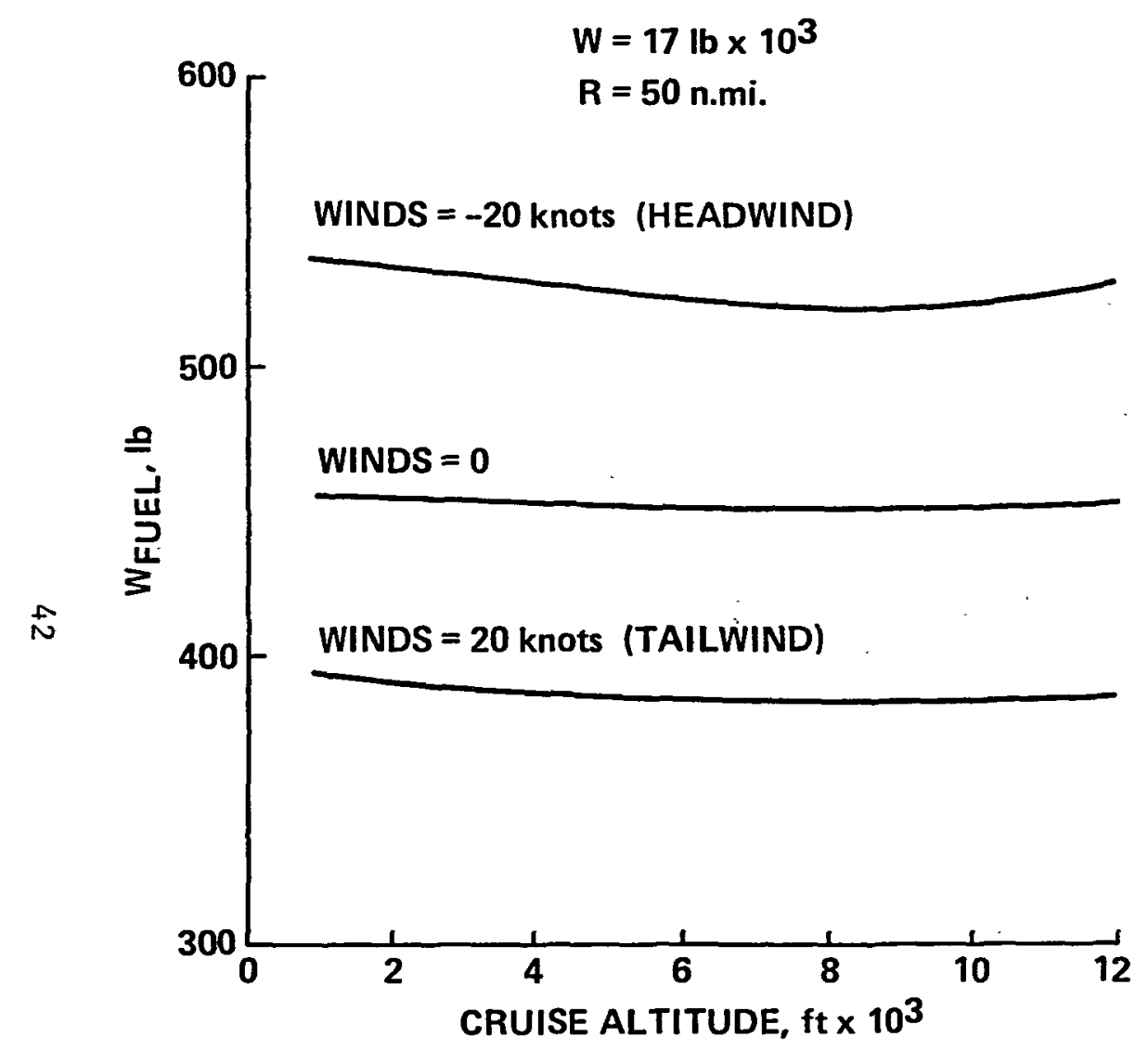

Figure 4.8.- Effect of constant wind on minimum fuel used.

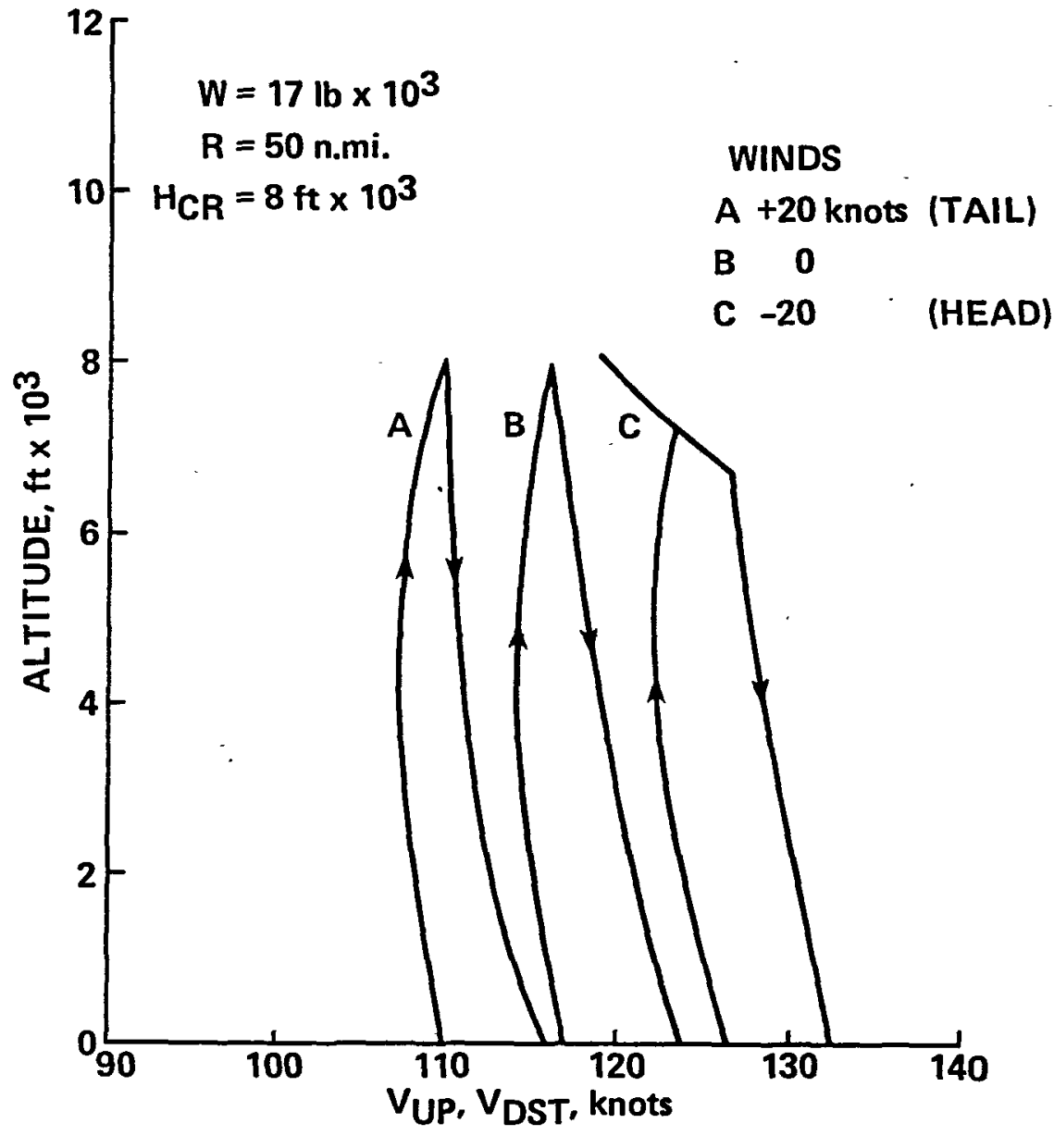

Figure 4.9.- Effect of wind on optimal ascent and descent airspeeds 


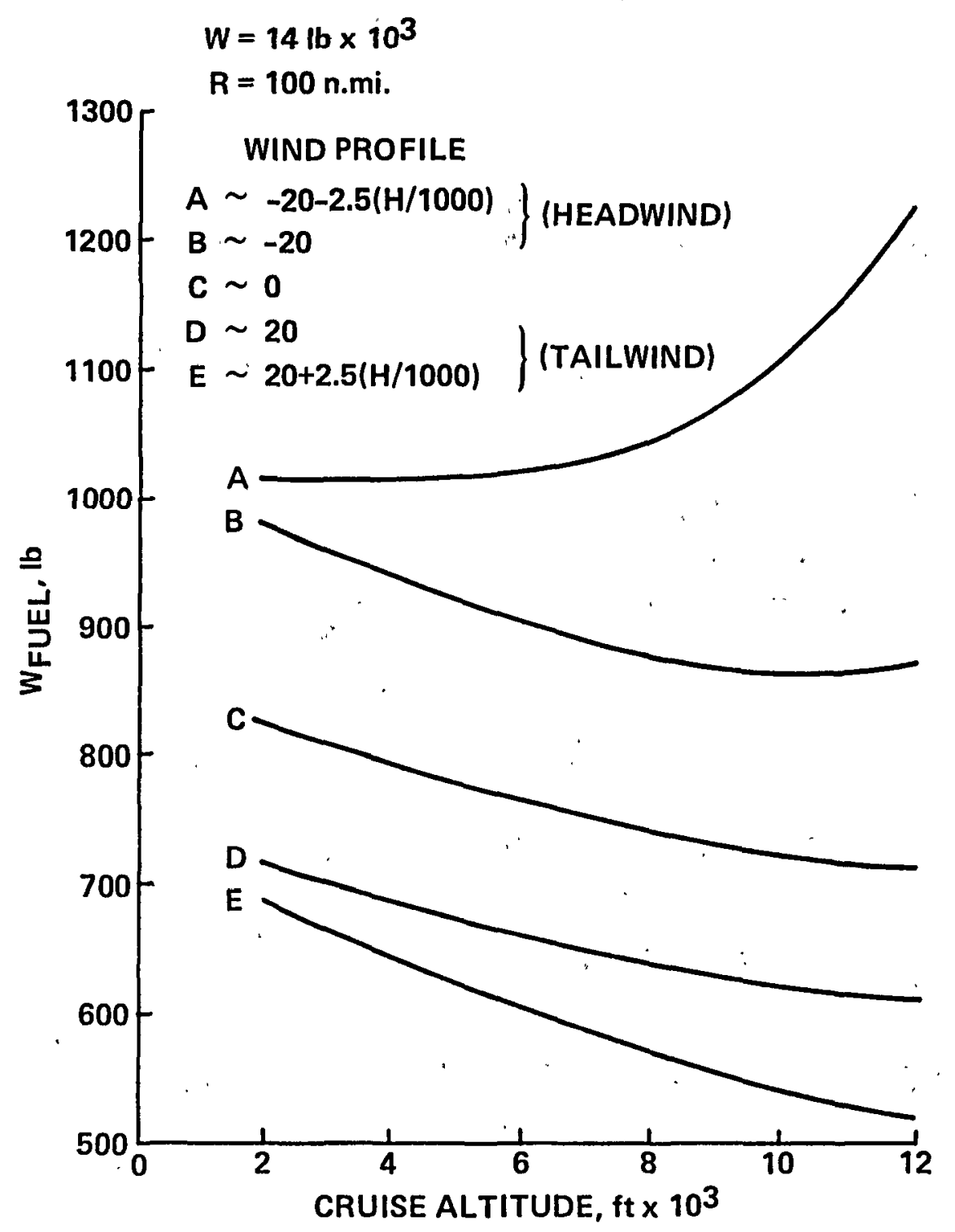

Figure 4.10.- Effect of wind on minimum fuel consumed during climb. 


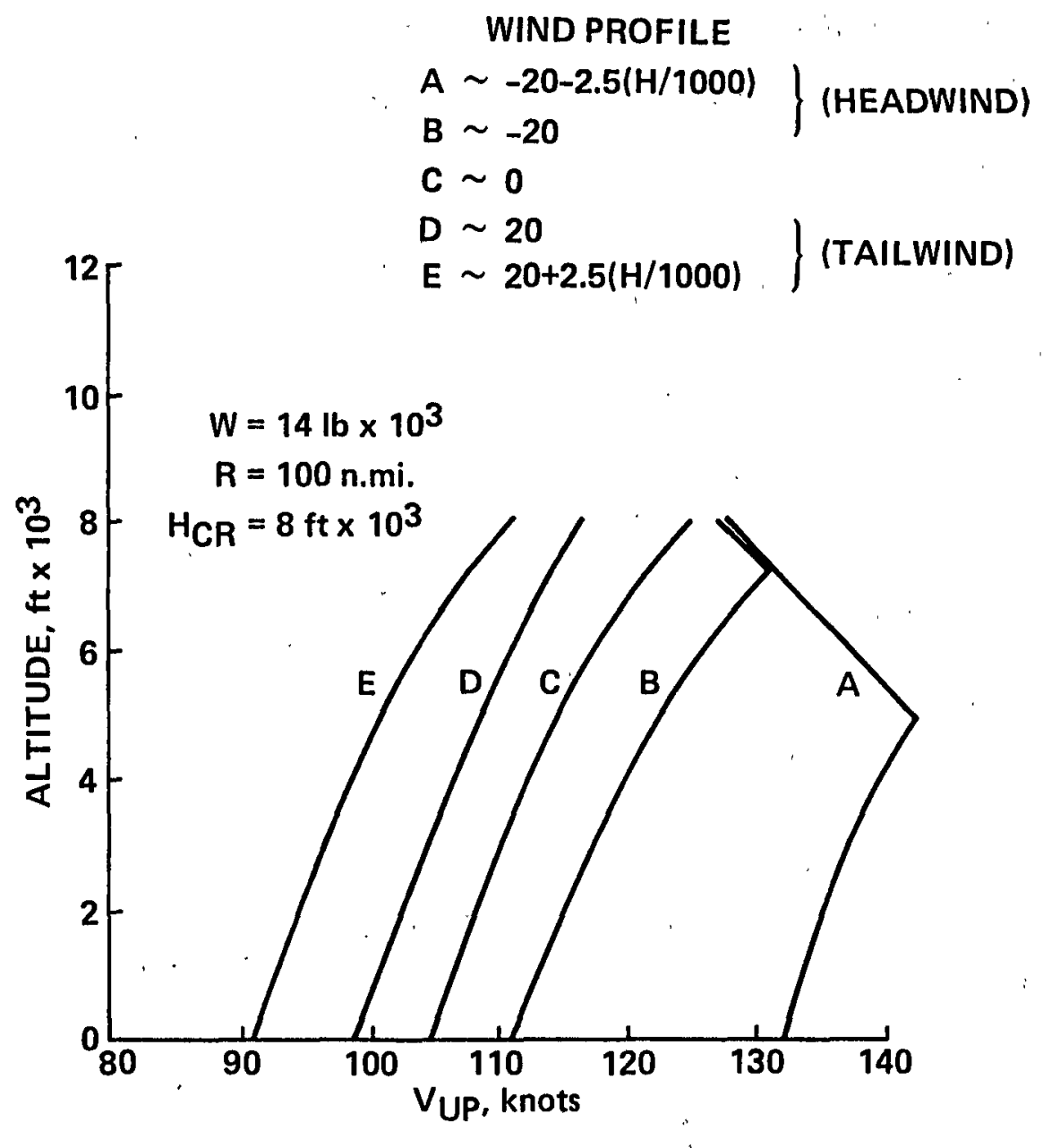

Figure 4.11.- Effect of wind on optimal ascent speed. 

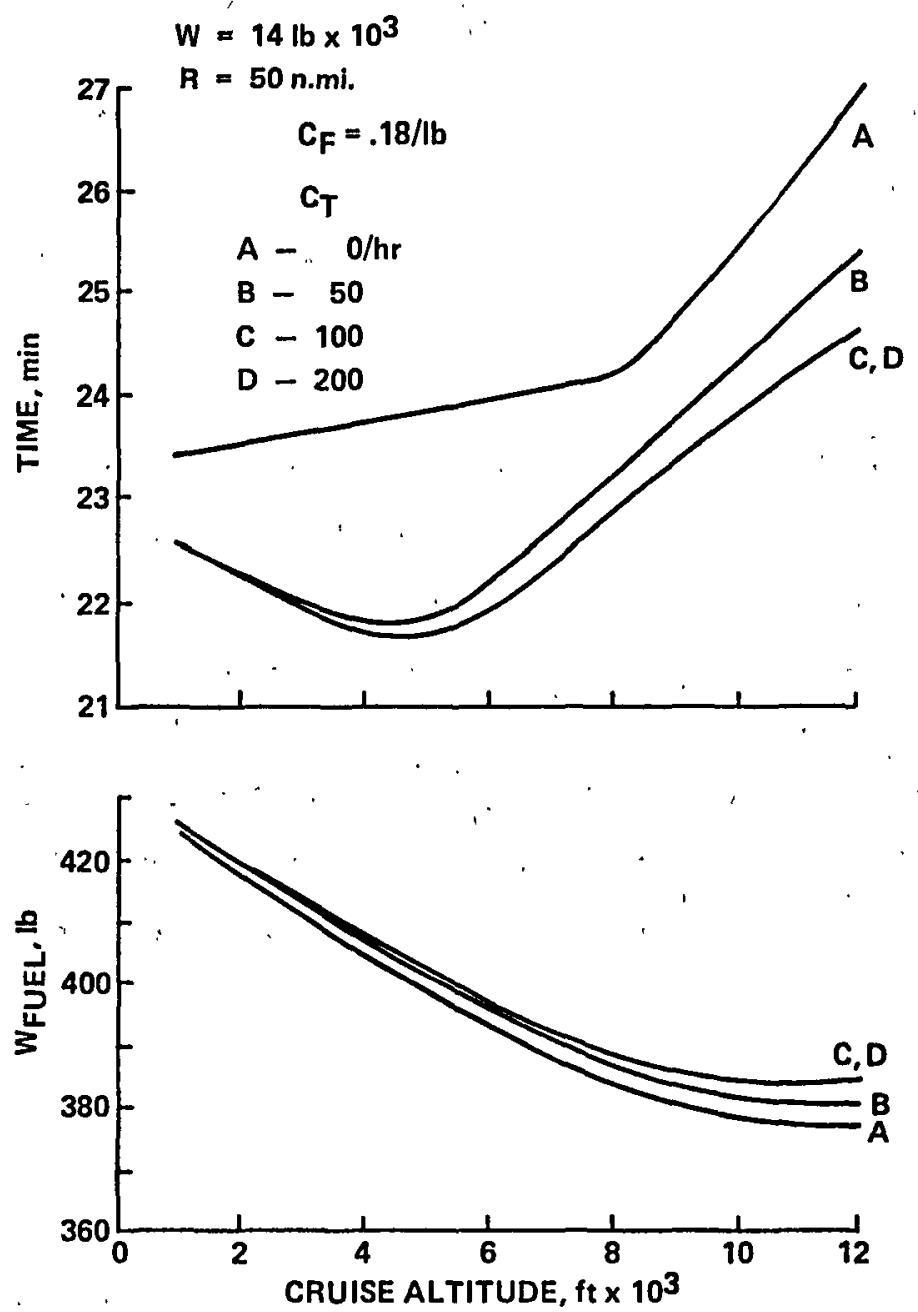

Figure 4.12.- Fuel and time on optimal trajectorles for various time weights, $C_{T}$. 


\begin{tabular}{|c|c|}
\hline $\begin{array}{l}\text { 1. Report No. } \\
\text { NASA TM-84303 }\end{array}$ & 3. Recipient's Catalog No. \\
\hline \multirow{2}{*}{$\begin{array}{l}\text { 4. Title and Subtitle } \\
\text { OPTIMAL SHORT-RANGE TRAJECTORIES FOR HELICOPTERS }\end{array}$} & $\begin{array}{l}\text { 5. Report Date } \\
\text { December } 1982\end{array}$ \\
\hline & 6. Performing Organization Code \\
\hline $\begin{array}{l}\text { 7. Author(s) } \\
\text { G. L. Slater* and H. Erzberger** }\end{array}$ & $\begin{array}{l}\text { 8. Performing Organization Report No. } \\
\text { A-9132 }\end{array}$ \\
\hline \multirow{2}{*}{$\begin{array}{l}\text { 9. Performing Organization Name and Address } \\
\text { *University of Cincinnat1, Cincinnat1, Ohfo } 45221 \text { and } \\
\text { **NASA Ames Research Center, Moffett Fleld, Calif. } 94035 \\
\text {. }\end{array}$} & $\begin{array}{l}\text { 10. Work Unit No. } \\
505-34-11\end{array}$ \\
\hline & 11. Contract or Grant No. \\
\hline \multirow{2}{*}{$\begin{array}{l}\text { 12. Sponsoring Agency Name and Address } \\
\text { National Aeronautics and Space Administration, } \\
\text { Washington, D.C. } 20546\end{array}$} & $\begin{array}{l}\text { 13. Type of Report and Period Covered } \\
\text { Techn1cal Memorandum }\end{array}$ \\
\hline & 14. Sponsoring Agency Code \\
\hline
\end{tabular}

15. Supplementary Notes

Point of Contact: H. Erzberger, NASA Ames Research Center, Moffett Field, Cal1f. 94035, M/S 210-9.

16. Abstract

An optimal flightpath algorithm using a simplified altitude state model and an a priorl climbcruise-descent flight profile has been developed and applied to determine minimum fuel and minimum cost trajectorles for a helicopter flying a fixed-range trajectory. In addition, a method is developed for obtaining a performance model in simplified form which is based on standard filghtmanual data and which is applicable to the computation of optimal trafectories. The entire performance-optimization algorithm is simple enough that on-1ine trajectory optimization is feasible with a relatively small computer.

The helicopter model used in this study is the sikorsky S-61N. The results show that for this vehicle the optimal flightpath and optimal cruise altitude can represent a $10 \%$ fuel saving on a minimum-fuel trajectory. The optimal trajectorles show considerable variability because of hel1copter welght, ambient winds, and the relative cost trade-off between time and fuel. In general, "reasonable" variations from the optimal velocities and cruise altitudes do not significantly degrade the optimal cost.

For fuel-optimal trajectorles, the optimum cruise altitude varies from the maximum $(12,000 \mathrm{ft})$ to the minimum $(0 \mathrm{ft})$ depending on helicopter weight. If time of flight is an Important component of the cost function, then significant reductions in flight time from the minimum-fuel trajectory are achleved with only minor increases in fuel cost.

\begin{tabular}{|c|c|c|c|c|}
\hline $\begin{array}{l}\text { 17. Key Words (Suggested by Author(s)) } \\
\text { Hellcopters } \\
\text { Optimum flightpaths } \\
\text { Fuel optimlzation }\end{array}$ & & $\begin{array}{l}\text { 18. Distribution Statement } \\
\text { Unlimited }\end{array}$ & Subject Category & (2) \\
\hline $\begin{array}{l}\text { 19. Security Classif. (of this report) } \\
\text { Unclassiffed }\end{array}$ & $\begin{array}{l}\text { 20. Security Classif. lof } \\
\text { Unclassified }\end{array}$ & if this page) & $\begin{array}{l}\text { 21. No. of Pages } \\
51\end{array}$ & $\begin{array}{l}\text { 22. Price" } \\
\text { A04 }\end{array}$ \\
\hline
\end{tabular}

"For sale by the National Technical Information Service, Springfield, Virginia 22161 